Language input and brain responses in bilingual and monolingual infants

Relationships Between Quantity of Language Input and Brain Responses

in Bilingual and Monolingual Infants

\author{
Adrian Garcia-Sierra ${ }^{a}$ \\ Nairan Ramírez-Esparza ${ }^{\mathrm{b}}$ \\ Patricia K. Kuhl ${ }^{\mathrm{c}}$
}
${ }^{a}$ Speech, Language and Hearing Sciences, University of Connecticut 850 Bolton Road. Unit 1085 Storrs, CT 06269, USA
${ }^{\mathrm{b}}$ Department of Psychological Sciences, University of Connecticut 406 Babbidge Road. Unit 1020 Storrs, CT 06269, USA
${ }^{\mathrm{c}}$ Institute for Learning \& Brain Sciences, University of Washington, 1715 Columbia Road N. Portage Bay Building Box 357988, Seattle, WA 98195, USA

Corresponding address:

Adrian Garcia Sierra University of Connecticut 850 Bolton Dr. Unit 1085

Storrs, Connecticut 06269

adrian.garcia-sierra@ucon.edu 
Language input and brain responses in bilingual and monolingual infants

\begin{abstract}
The present investigation explored the relation between the amount of language input and neural responses in English monolingual $(\mathrm{N}=18)$ and Spanish-English bilingual $(\mathrm{N}=19)$ infants. We examined the mismatch negativity (MMN); both the positive mismatch response (pMMR) and the negative mismatch response (nMMR), and identify a relationship between amount of language input and brain measures of speech discrimination for native and non-native speech sounds (i.e., Spanish, English and Chinese). Brain responses differed as a function of language input for native speech sounds in both monolinguals and bilinguals. Monolingual infants with high language input showed nMMRs to their native English contrast. Bilingual infants with high language input in Spanish and English showed pMMRs to both their native contrasts. The non-native speech contrast showed different patterns of brain activation for monolinguals and bilinguals regardless of amount of language input. Our results indicate that phonological representations of non-native speech sounds in bilingual infants are dependent on the phonetic similarities between their native languages.
\end{abstract}

Key words= Bilingual infants, Event Related Potentials, Mismatch Response, Language Learning, Amount of Language Input, Speech Discrimination 
Language input and brain responses in bilingual and monolingual infants

\section{Relationships Between Quantity of Language Input and Brain Responses in Bilingual and Monolingual Infants}

During the first year of life, the brain undergoes a profound reorganization that is dependent on input. The reorganization has been referred to as language neural commitment or perceptual narrowing. Early in life infants are able to discriminate speech sounds from all languages, regardless of their language experience. As infants receive more language input they remain perceptually sensitive only to speech-sound differences within their native language (Aslin, Pisoni et al., 1981; Eilers, Gavin, \& Wilson, 1979; Eilers, Wilson, \& Moore, 1977; Werker \& Tees, 1984; Kuhl et al., 1992; Kuhl et al., 2006). In recent years there has been an upsurge of studies evaluating neural commitment in bilingual infants. The methods and approaches used in these studies are diverse, but in general these studies indicate that bilingual experience leads to heightened perceptual sensitivities (Byers-Heinlein, Burns, \& Werker, 2010; Gervain \& Werker, 2013; Krizman, Shafer, Yu, \& Datta, 2011; Sebastián-Gallés, AlbaredaCastellot, Weikum, \& Werker, 2012; Skoe, Marian, \& Kraus, 2014; Weikum et al., 2007). Heightened perceptual sensitivities in bilinguals have been interpreted as the result of "extra work" involved in differentiating and learning the speech-sounds from both of their native languages. In addition, the timing of neural commitment can differ in bilinguals compared to that observed in their monolingual peers due to the increased computations associated with learning two languages (see Werker, 2012; Werker \& Hensch, 2015 for a review). 
Language input and brain responses in bilingual and monolingual infants

The present investigation explores neural commitment in monolinguals and bilinguals by relating brain measures of speech discrimination to native and non-native speech sounds with the amount of language input infants receive in their homes. Language input is assessed with digital recordings of the speech infants hear in their everyday lives. Discrimination of native and nonnative speech sounds is assessed by analyzing mismatch negativity (MMN); both the positive mismatch response (pMMR) and the negative mismatch response (nMMR). We evaluated similarities and differences in the patterns of brain activation to native and non-native speech sounds of monolinguals and bilinguals of the same age, but with different language experience.

\section{Electrophysiological Measures of Neural Commitment}

Brain responses associated with speech discrimination are reliable neural markers of language development and cortical maturation. In contrast to behavioral paradigms, brain measures provide a continuous record of the response to a stimulus, allowing more detailed evaluation of the effects of specific experimental manipulations (Luck, 2014; Osterhout, Bersick, \& McLaughlin, 1999; Shtyrov \& Pulvermüller, 2007). Brain measures of neural commitment in infants have employed Event Related Potentials (ERPs) in the form of the MMN (Näätänen, 1992). The MMN is an excellent tool to explore infants' neural commitment because it is a brain response that is elicited with passive listening and indicates the brain's ability to automatically detect a change in the auditory signal (Cheour, Leppänen, \& Kraus, 2000; Näätänen, 1986; 1990; 1992; Näätänen, Gaillard, \& Mantysalo, 1978; Näätänen \& Michie, 1979; Näätänen, Simpson, \& Loveless, 1982). The MMN is elicited by two sounds: a standard or background sound that establishes an auditory memory trace and a deviant or target sound that differs from the standard 
Language input and brain responses in bilingual and monolingual infants (e.g., in frequency, localization, duration, intensity, etc.). The degree of perceived difference between the standard and the deviant sound is reflected by the amplitude change of the MMN. The amplitude of the response becomes larger as the acoustic difference between standard (memory trace) and deviant increase (Tiitinen, May, Reinikainen, \& Näätänen, 1994). The adult MMN is present approximately $200 \mathrm{~ms}$ after stimulus onset. The MMN follows the same pattern of maturation as other ERP measures; that is, the amplitude of the MMN increases and the latency decreases with age (Gomes et al., 1999; Kushnerenko et al., 2002; Morr, Shafer, Kreuzer, \& Kurtzberg, 2002; Shafer, Morr, Kreuzer, \& Kurtzberg, 2000; Trainor et al., 2003). Infant studies of auditory discrimination report MMNs approximately 350-550ms after stimulus onset. Infant studies of speech perception have used the MMN to assess the existence of language-specific phonemic memory traces in the brain. For example, a strong MMN is elicited when 12-month-old infants listen to sounds of their native language, and it is reduced when they listen to non-native speech sounds that do not represent phonemic categories in their native phonology (Cheour et al., 1998; Näätänen et al., 1997). The infant MMN to native speech sounds has been interpreted as evidence that highly accurate sensory information for the native language sounds has been processed and mapped onto the native phonology (Cheour-Luhtanen et al., 1995; Cheour et al., 1997; 1998; Froyen, Bonte, van Atteveldt, \& Blomert, 2008; Näätänen et al., 1997; Zachau et al., 2005). Simply put, the infant MMN suggests neural commitment to the sounds of the native language (Kuhl et al., 2008).

The infant MMN literature also reports a response with positive polarity occurring at a shorter latency (150-350 ms after stimulus onset). The positivity has been interpreted as a brain 
Language input and brain responses in bilingual and monolingual infants response specific to early discrimination, perhaps an acoustic form of analyses preceding phonemic representation (Rivera-Gaxiola, Silva-Pereyra, \& Kuhl, 2005; Ferjan Ramírez, Ramírez, Clarke, Taulu, \& Kuhl, 2016). For example, Ferjan Ramirez et al. (2016) recorded brain responses (MEG) from 11 month-old English monolingual and Spanish-English bilingual infants to an English and Spanish contrast. Both groups showed stronger brain responses to the English contrast, however, the stronger response in monolinguals took the form of nMMRs while the stronger response in bilinguals took the form of pMMRs. The results were interpreted as monolinguals showing advanced commitment to their native language while bilinguals show a slower transition from acoustic to phonemic sound representation (Rivera-Gaxiola,et al., 2005). Ferjan Ramirez and colleagues found that monolinguals' brain activity was widespread in the frontal areas of both hemispheres, whereas bilinguals' brain activity was restricted to left auditory areas. In other words, monolinguals showed a more complex processing of the speech signal while bilinguals' processing involved a more acoustic form of analysis.

The infant pMMR has also been intrpreted as a special effort in processing acoustic deviance (Friedrich, Weber, \& Friederici, 2004). For example, Liu, Chen, \& Tsao (2014) compared MMNs from Mandarin monolingual preschoolers (3.5y), school children (8.5y), and adults (22.5y) to a difficult Chinese contrast (an alveolo-palatal affricate /tchi / and an alveolopalatal fricative /6i/). The results showed positive MMRs (pMMR) for both groups of children and adult-like MMNs for adults suggesting that children require longer periods of time to learn the acoustic properties of speech sounds with complex acoustic properties. The pMMR response has also been interpreted as a less mature response, when compared to the adult MMN, since the 
Language input and brain responses in bilingual and monolingual infants positivity declines with age and the adult-like MMN emerges later in development (Morr et al., 2002; Trainor et al., 2003). Overall, the amplitude of the pMMR has been shown to be dependent on language experience (Cheour et al., 1997; 1998; Dehaene-Lambertz \& Dehaene, 1994; Dehaene-Lambertz \& Baillet, 1998; Ferjan Ramirez et al., 2016; Friederici, Friedrich, \& Christophe, 2007; Rivera-Gaxiola, Silva-Pereyra et al., 2005;) maturational factors (Kushnerenko et al., 2002; Leppänen, Eklund, \& Lyytinen, 1997; Maurer, Bucher, Brem, \& Brandeis, 2003; Morr et al., 2002; Trainor et al., 2003) and discriminability of the signals (Lee et al., 2012; Cheng et al., 2013; 2015).

Researchers have agreed to describe the long latency infant MMN as the negative Mismatch Response (nMMR) and the positive MMN with early latency as the positive Mismatch Response (pMMR) in children (Friedrich, et al., 2004; Liu, eta la., 2014; Lee et al., 2012; Cheng et al., 2015; Shafer, Yu, \& Garrido-Nag, 2012). The present investigation will use these labels going forward.

The Role of Attention in the MMR

Research on infants' auditory discrimination abilities has shown that the pMMR and nMMR can coexist in the same group of participants suggesting that cortical maturation is not the only factor explaining the presence of the pMMR. For example, Lee et al. (2012) presented lexical tones, vowels, and stop consonants to a group of 4-6-year-old Taiwanese Mandarinspeaking children. The results showed nMMRs for the lexical tones and vowels, but pMMRs for consonants; suggesting the pMMR is also dependent on the characteristics of the stimuli. In a relevant study, Cheng and colleagues (2015) investigated the interaction between brain 
Language input and brain responses in bilingual and monolingual infants maturation and stimulus characteristics by testing 3 groups of Chinese monolinguals; newborns, 6 month-old infants, and adults. Participants were tested on a set of consonant-vowel contrasts that were easy or hard to discriminate based on the length of the vowel (long and short vowels, respectively). The newborns showed pMMRs for both types of stimuli, while 6 month-olds showed pMMRs only for the difficult contrast and nMMRs only for the easy contrast. Adults, on the other hand, showed MMNs for both types of stimuli. The coexistence of pMMRs and nMMRs in the 6 month-old infants was interpreted as infants being able to "automatically" process the easy contrast, but lacking the resources to automatically engage in the processing of the difficult contrast.

Jusczyk (2000) proposed the idea that speech perception becomes more automated with development. It is well documented that language learning in infants involves an interaction between language input and the underlying perceptual capacities. Over time, as infants receive more input and their brains mature, their attentional abilities facilitate the development of native language speech perception, including phonetic sequences (Jusczyk et al., 1993) and word prosody (Juszyk, Cutler, \& Redanz, 1993), with attention to specific aspects of language becoming more and more automatic with increased experience. For example, Gomes et al. (2000) collected MMNs from adults and children (8-10 y.) in response to 3 deviant tones that were easy, medium, and hard to discriminate from a standard tone. MMNs were collected during a passive listening condition (e.g., while watching a movie) and during an attending condition (i.e., participants pressed a button when detecting deviants). The results showed comparable MMN-effects in children and adults. However, children showed larger MMNs for the hard-to- 
Language input and brain responses in bilingual and monolingual infants discriminate deviant during the attending than during the passive listening condition. These results were interpreted as evidence that auditory discrimination of difficult contrasts is initially a controlled, attention-demanding process that becomes automatic with experience. Similar results were obtained by Hisagi, Shafer, Strange, and Sussman (2010) who recorded MMNs from English monolingual and Japanese monolingual adults to changes in vowel durations that are phonemic only in Japanese. The MMNs were collected during a passive listening and an attending condition. The results showed MMN amplitude differences across conditions only for the English speakers. Namely, English speakers showed reduced MMNs during the passive listening condition when compared with the attending condition. In contrast, Japanese speakers did not show amplitude differences between conditions. Overall, these studies support the notion that enhanced attentional demands are associated with difficult discrimination tasks, such as discrimination of non-native speech sounds, but are reduced with increasing experience as discrimination becomes more automated.

Strange (2011) proposes that infants rely on attentional mechanisms to develop selective perceptual routines (SPRs) that allow for efficient and automatic detection of native-language speech sound contrasts, in the same manner that adults experience extra attentional demands in the perception of non-native speech sounds. It is assumed that fully learned SPRs result in explicit cortical representation (i.e., nMMR) with low attentional demands while perceptual routines that are not fully learned require increased attention and are manifested in the form of pMMRs. 
Language input and brain responses in bilingual and monolingual infants

There are few MMN studies exploring infant attention during speech perception. Shafer, and colleagues (2012) recorded MMNs from 6 month-old English monolingual and SpanishEnglish bilingual infants in response to an English vowel contrast (/I/ as in "bit" and $/ \varepsilon /$ as in bet) in an attending $v s$. non-attending condition. The stimuli were presented in sequences of ten stimuli (trains) with a 1500 ms pause between trains. The deviant stimulus was presented in the $4^{\text {th }}, 5^{\text {th }}, 6^{\text {th }}, 8^{\text {th }}$ and, $10^{\text {th }}$ position. The assumption was that deviants occurring in the last positon would be easier to perceive (attending condition); whereas deviants occurring in middle position would be harder to perceive (non-attending condition). Overall, infants showed a larger nMMR during the attending condition than during the non-attending condition, and during the nonattending condition a pMMR was observed. These effects were present in both language groups, suggesting that increased attention to deviants during the attending condition lead to larger nMMRs, regardless of language experience. Similar findings were reported by Shafer et al. (2011) in a study which recorded MMNs from English monolingual and Spanish-English bilingual infants in response to the same vowel contrast described above (Shafer et al., 2012). While stimulus presentation was not manipulated to create an attending condition vs. nonattending condition, an increased negativity of the MMR was found for bilingual females compared to bilingual males. The authors postulated that since the female brain develops more rapidly than the male (Shucard \& Shucard, 1990), and since bilinguals have heightened perceptual sensitivities (Curtin, Byers-Heinlein, \& Werker, 2011), the bilingual females showed nMMRs due to having SPRs early in development. These findings support the idea that attending to the signal over time results in an nMMR response; that is, discrimination is initially a 
Language input and brain responses in bilingual and monolingual infants controlled attention-demanding process (pMMR) that becomes automatic (nMMR) with experience.

nMMR as a Function of Language Input

To our knowledge there is only one study that has analyzed the interaction between neural commitment (in the form of ERPs) and language input in infants exposed to two languages. Garcia-Sierra et al. (2011) recorded MMNs from infants exposed to English and Spanish (6-9 and 10-12-months of age) to an English speech contrast and a Spanish speech contrast that is not phonemic in English. In this study, bilingual infants showed increased nMMR amplitudes with increased age. More interesting was the reported relationship between the amount of language input (measured by parent reports) and neural commitment. Infants with higher English or higher Spanish language input showed differences in the amplitude of the nMMR response. Specifically, bilingual infants with high English input showed age effects for the nMMR in response to the English contrast: at 6-9 months of age the nMMR response was less negative, and at 10-12-months of age a strong negative nMMR response was observed. However, the strength of the nMMR to the English contrast did not change as a function of age in bilinguals with low English input. Similarly, bilingual infants with high Spanish input showed age effects for the nMMR in response to the Spanish contrast: at 6-9 months of age the nMMR response was less negative, and at 10-12-months of age a strong negative MMR was observed. Overall, a consistent neural pattern emerged for children in the high language input groups. That is, the nMMR becomes more negative as a function of the amount of language input and age. 
Language input and brain responses in bilingual and monolingual infants

Garcia-Sierra et al. (2011) also replicated the previously reported relationships between neural commitment and later word production (Kuhl et al., 2008; Rivera-Gaxiola, Klarman, Garcia-Sierra, \& Kuhl, 2005). Bilingual infants who showed stronger neural commitment to English speech sounds at lateral-frontal electrode sites (i.e., a strong nMMRs) produced more words in English as toddlers. Likewise, infants who showed stronger neural commitment to Spanish speech sounds produced more words in Spanish as toddlers.

While Garcia-Sierra and colleagues (2011) provided information about the processes of neural commitment in bilinguals as a function of language input, important questions remain unanswered. For example, while the response to non-native speech sounds has been documented in monolingual infants, the response to non-native speech sounds in bilingual infants has not been examined. Furthermore, in previous studies, bilingual infants' relative language input in the two native languages has been assessed only by means of parental reports, not by direct observation, and there are no monolingual studies of MMN as a function of the amount of language input. The present study addresses these questions by including both monolingual and bilingual infants, collecting ERP data in response to native speech contrasts and to a speech contrast that is non-native for both monolingual and bilingual participants, and assessing language input in a more systematic way by using a digital recorder to capture speech directed to the infant by the mother and the father in a natural setting.

\section{Study Overview}

The goal of the present study was to assess neural commitment as a function of language input. We argue that increased language input to monolingual and bilingual infants in their 
Language input and brain responses in bilingual and monolingual infants everyday lives facilitates commitment to their native language or languages. In order to accomplish this goal, we examined the pMMR and nMMR of English monolingual and SpanishEnglish bilingual infants at 11 and 14 months of age as a function of the amount of language input they receive in natural settings, and in response to both native and non-native speech contrasts. This required 3 contrasts; 1 native (i.e., an English contrast) and 2 non-native (i.e., a Spanish and Chinese contrast) for monolinguals, 2 native (i.e., an English contrast and a Spanish contrast) and 1 non-native (i.e., a Chinese contrast) for bilinguals.

The present study reports ERP amplitudes in the following ways. First, the amplitudes from the Standard and Deviant ERP responses in the 150-350 and 350-550 ms time window are compared to investigate increased attention to the speech signal (pMMR) and language commitment (nMMR) for native speech sounds; respectively. Second, the difference waveforms (Deviant minus Standard) for the same time windows are calculated and correlated with the amount of language input infants receive at home. Third, we compare the amplitude of the pMMR difference waves with the amplitude of the nMMR difference waves (pMMR / nMMR amplitude differentiation) as a way to explore the characteristics of the neural patterns associated with language commitment.

\section{Expected Outcomes}

Monolinguals and Bilinguals Brain Responses to Native Speech Sounds. We propose that the amount of language input infants receive in their everyday lives influences the development of selective perceptual routines for the native speech sounds. Therefore, infants will show different levels of attentional demand during native language syllable processing depending on 
Language input and brain responses in bilingual and monolingual infants the amount of language input received at home. Infants receiving high amounts of language input will have developed efficient selective perceptual routines to differentiate native speech sounds, reducing attentional demands. In this scenario, nMMRs are expected. On the other hand, infants with low amounts of language input will experience high attentional demands during speech signal processing, and pMMRs are expected. Therefore, we expect to find a relationship between the amount of language input and the amplitude of the pMMR and nMMR.

\section{Monolingual Brain Responses to Non-Native Speech Sounds. We expect that}

monolingual infants will show different brain responses to each of the non-native contrasts. The Spanish contrast tested in the present investigation (/da-ta/; see methods) represents a single phonemic category in the English language (i.e., /da/) and therefore, monolingual infants are likely to assimilate it into a single phonetic category (Antoniou, Tyler, \& Best, 2012; Best, 1992). Stop consonants are very frequent in the English language and monolingual infants have likely established selective perceptual routines for stop consonants. Therefore, we predict reduced pMMRs and reduced nMMRs.

The Chinese contrast is composed of an alveolo-palatal affricate $\left(/ \mathrm{tc}^{\mathrm{h}} \mathrm{i} /\right)$ and an alveolopalatal fricative (/6i/). These sounds are not part of the English phonology and therefore will be perceptually assimilated to the closest English phonemic category (perhaps the affricate postalveolar or fricative palatal; [t \& J] respectively; see Mines, Hanson, \& Shoup, 1978). Unlike stop consonants, the English fricative and affricate consonants are much less frequent in the English language. Consequently, infants have less experience with these sounds and it is unlikely they have established perceptual routines for affricate and fricative English sounds. In 
Language input and brain responses in bilingual and monolingual infants accordance with Strange (2011) and Shafer et al. (2012), the Chinese contrast should produce positive-MMRs with no observable nMMRs.

Finally, we expect no relationship between the amount of language input infants receive at home and the amplitude of the pMMR or nMMR for the non-native Spanish and Chinese contrasts.

Bilingual Brain Responses to Non-Native Speech Sounds. Bilingual infants' perceptual assimilation of the Chinese contrast is expected to differ from that of monolingual infants because bilinguals have multiple categories to perceptually represent the Chinese contrast based on their experience in English and Spanish: an affricate-fricative contrast in English (i.e., [ $\left[\mathrm{f} \& \int\right]$ ) and a postalveolar affricate in Spanish (i.e., $[\mathrm{t}]$ ]). Furthermore, in the Spanish language context, both $[\mathfrak{g}]$ and $[f]$ speech productions would be members of the phoneme $/ \mathfrak{t} /$. Therefore, bilinguals have more experience with affricates, and less experience with fricative-affricate contrasts which may result in bilinguals having established perceptual routines for affricates. We hypothesize that bilinguals will assimilate the Chinese fricative-affricate contrast into a single category based on their experiences with their 2 native languages, and no pMMRs or nMMRs are expected. In other words, bilingual brain responses to the Chinese contrast are expected to be similar to the brain responses obtained from monolinguals to the Spanish contrast. Also, bilinguals' brain responses to the Chinese contrast is not expected to be related with the amount of language input infants receive at home.

\section{Methods}

\section{Participants}


Language input and brain responses in bilingual and monolingual infants

The participants were 27 monolingual (13 females, 14 males) and 27 bilingual (14

females, 13 males) infants. Not all participants had usable ERPs in all three conditions (see below); therefore, the final sample was 18 monolingual ( 9 females, 9 males) and 19 bilingual (10 females, 9 males $)$ infants. Two age groups, 11 months $(\mathrm{N}=9$ monolinguals, and $\mathrm{N}=12$ bilinguals; age range 11 months and 6 days to 11 months and 15 days) and 14 months ( $\mathrm{N}=9$ monolinguals and 7 bilinguals; age range 13 months and 27 days to 14 months and 8 days), were recruited as part of a large-scale study at the Institute for Learning \& Brain Sciences in Seattle, WA. Socioeconomic status (SES) was assessed using the Hollingshead index (Hollingshead, 2011), a widely used measure producing an overall SES score based on parental education level and occupation (monolinguals' Mean $=57.06, \mathrm{SD}=5.94$; bilinguals' Mean $=43.03, \mathrm{SD}=17.70$; Range $=16-66)$. Participants were full-term (37-43 weeks) infants with normal birth weight (2.5-4.5 kg) and no major birth/postnatal complications.

Participants were informed about the procedures, signed approved consent forms, and participated in three ERP data collection sessions (i.e., one data collection session for each contrast: English, Spanish, and Chinese). The first speech contrast assessed was always English. Spanish and Chinese ERP data collection sessions followed and were counterbalanced across participants. All participants had 3 usable ERPs except for one participant with 2 usable ERPs (a 14 month-old bilingual English contrast was missing).

Language and Cultural Characteristics of the Bilingual Families

Our English/Spanish bilingual background questionnaire (Garcia-Sierra, Diehl, \& Champlin, 2009; García-Sierra, Ramírez-Esparza, Silva-Pereyra, Siard, \& Champlin, 2012) 
Language input and brain responses in bilingual and monolingual infants assessed bilingal parents' level of confidence in speaking and understanding English and Spanish. Participants were asked to rate their overall confidence in speaking and understanding English and Spanish using a 1-5 Likert scale ( 1 = "I cannot speak the language, I have a few words or phrases, and I cannot produce sentences"; 5 = "I have a native-like proficiency with few grammatical errors and I have good vocabulary"). The overall mean for bilingual caregivers' confidence in speaking English was $4.4(\mathrm{SD}=.72)$ and $4.7(\mathrm{SD}=.63)$ for Spanish. The overall mean for bilingual caregivers' in understanding English was $4.5(\mathrm{SD}=.72)$ and 4.7 $(\mathrm{SD}=.63)$ for Spanish

\section{Language input assessment}

The language input was quantified based on digital first person audio recordings of the infants collected over 4 consecutive days. Language input was assessed by means of the Language Environment Analysis System (LENA foundation, Boulder Colorado) which includes a digital language processor (DLP) that can store up to 16 hours of digitally recorded sound. The DLP weighs $3 \mathrm{oz}$. and can be snapped into a chest pocket in children's clothing, allowing the recorder to be "out of sight, out of mind". The audio recordings are downloaded to a computer and analyzed by LENA software to characterize the acoustic environment over time, allowing us to efficiently identify segments of language activity, which were then coded for the language in the environment (English and/or Spanish). For the purposes of the present investigation, parents received two DLPs and were instructed to record continuously during 4 consecutive days (two weekdays and two weekend days), eight hours each day for a total of approximately 32 hours of recorded audio data. 
Language input and brain responses in bilingual and monolingual infants

Data preparation. The audio data were transferred from the DLP to a computer and analyzed by LENA software employing advanced speech-identification algorithms that automatically analyze audio files and produce reports of language activity. The audio files were then further processed using the LENA Advanced Data Extractor Tool (ADEX) in order to efficiently identify short intervals with the language activity of interest (i.e., adult speech) for transcribing, and eliminate intervals that did not qualify. This tool provides outputs for individual speech segments as short as a fraction of a second. It was used to segment each participant's large dataset of recorded audio into 30-second intervals, and to automatically calculate an adult word count for each interval. Intervals with zero adult words are removed and 40 intervals that are at least 3-minutes apart are selected from the remaining intervals across the entire day, chosen from those with the highest adult word counts (see Ramírez-Esparza, Garcia-Sierra \& Kuhl, 2014, for more information).

Six research assistants ( 3 monolingual and 3 Spanish-English bilingual) were trained to transcribe the selected intervals for each participant. Transcribers were provided with basic information about each selected interval (date, day of the week, time of day, and the time stamp of the audio recording). Transcribing software played the specific 30 -second interval for transcribing based on the time stamp entered. Coders produced word for word transcriptions of speech produced by mothers and fathers during selected intervals. Speech produced by other adults was not transcribed because other adults had not provided informed consent. English and Spanish words were transferred to independent files, and the words were counted using the word count tool, yielding the total number of words spoken by the mother and/or father in English 
Language input and brain responses in bilingual and monolingual infants

and/or Spanish.

For the monolingual group the average word-count produced by both parents during coded intervals in English was 5,455.00 (SD = 1252.00). For the Spanish-English bilingual group the average word-count of words produced by both parents in English was 2,033.90 $(\mathrm{SD}=$ 1,836.88) and in Spanish was 2,038.10 ( $\mathrm{SD}=1,371.70)$. For Spanish-English bilingual group the average word-count of words produced by both parents in English plus in Spanish was 4,072.00 $(\mathrm{SD}=1,414.55)$. Independent $\mathrm{t}$ tests showed that monolingual parents used more significantly words than bilingual parents $(t(35)=3.14, \mathrm{p}=.003){ }^{1}$

Language Input Groups. Monolingual and bilingual infants were sorted into high or low language input groups based on a median-split of parental word count in each of their native language(s). For monolinguals, the median was 5,458.5 for the English word count. For bilinguals, the median was 1,246 for the English word count and 2,105 for the Spanish word count. The median split groupings revealed 2 bilinguals with high English and Spanish language input, 7 bilinguals with high English input and low Spanish input, 7 bilinguals with high Spanish input and low English input, and 3 bilinguals with low input in both languages. Table 1 shows the mean and standard deviation for the word-count obtained from monolingual and bilingual caregivers as a function of language input groups (high and low). Please note that the high and low Language-Input groups are calculated from parental word-counts of infants included in the ERP analyses.

\section{Brain measurements of speech discrimination}

Event-related potentials were recorded at the University of Washington at the Institute for 
Language input and brain responses in bilingual and monolingual infants

Learning \& Brain Sciences. Infants were tested with 3 different speech contrasts, each on a separate day. In the first session, infants' ERPs were collected in response to an English contrast (/ta/ vs. /pa/); in the second and third sessions, Spanish (/ta/ vs. /da/) and Chinese (/6i/ vs. $\left./ \mathrm{t}^{\mathrm{h}}{ }_{\mathrm{i}}^{\mathrm{i}} /\right)$ contrasts were presented in counterbalanced order.

Stimuli

The 3 speech stimuli used were synthesized using the cascade/parallel model for speech synthesis (Klatt, 1980). Based on the fact that each of the acoustic properties of the 3 speech contrast are very different, we analyze and report group differences for each speech contrast independently.

English Contrast. An English place of articulation stop consonant contrast (/pa/, /ta/) was used (Deviant, Standard; respectively). The syllables differed in the second through fourth formant transitions (F2, F3, and F4) from the consonant onset; both syllables had a first formant (F1) of $350 \mathrm{~Hz}$ at the consonant release. Beginning F2, F3, and F4 values for /pa/ were 850, 2400, and $3150 \mathrm{~Hz}$, respectively; values for /ta/ were 2300,3550 , and $4500 \mathrm{~Hz}$, respectively. Thus, the formant transitions for F2, F3, and F4 for /pa/ were rising toward the vowel, and these formants were falling toward the vowel for /ta/. Total syllable duration was $285 \mathrm{~ms}$; steady state vowel formant frequencies were 710, 1200, 2545, and $3290 \mathrm{~Hz}$; bandwidths were 110, 80, 175, and 360 $\mathrm{Hz}$, respectively; and pitch contours were identical, with a fundamental frequency of $135 \mathrm{~Hz}$ at the beginning of the vowel and tapering down to $95 \mathrm{~Hz}$. Tokens were equalized in RMS amplitude and played to infants at a comfortable listening level of $67 \mathrm{dBA}$ (see Kuhl et al., 2005). 
Language input and brain responses in bilingual and monolingual infants

Spanish Contrast. A Spanish voicing stop consonant contrast (/da/, /ta/) that is not phonemic in English was used (Deviant, Standard; respectively). The syllables differed only in their voice onset time (VOT), the primary acoustic cue for the voicing distinction, resulting in different vowel durations for each sounds. The prevoiced speech sound had $50 \mathrm{~ms}$ of voicing (negative VOT) and syllable duration of $175 \mathrm{~ms}$. The voiceless unaspirated speech sound ( 0 VOT) had a syllable duration of $225 \mathrm{~ms}$. Other than this, both speech tokens were identical. Syllables had a first formant (F1) of $500 \mathrm{~Hz}$ at the consonant release. Beginning F2, F3, and F4 values for both consonants were approximately 1550,2500 , and $3800 \mathrm{~Hz}$, respectively. The steady state vowel formant frequencies for F1 to F4 were 800, 1280, 2200, and $3800 \mathrm{~Hz}$, and bandwidths were 50,60,90, and $140 \mathrm{~Hz}$, respectively. Pitch contours were identical during the vowel portion with a fundamental frequency of $110 \mathrm{~Hz}$ at the beginning of the vowel and tapering down to $95 \mathrm{~Hz}$. Tokens were equalized in RMS amplitude and played to infants at a comfortable listening level of $67 \mathrm{dBA}$.

Chinese Contrast. An alveolo-palatal affricate (/t $\mathrm{h}_{\mathrm{i}}^{\mathrm{i}} /$ ) and an alveolo-palatal fricative (/6i/) Mandarin Chinese consonant contrast that is not phonemic in English or Spanish were used (Deviant, Standard; respectively). The syllables were $375 \mathrm{~ms}$ in duration; had identical steadystate vowel formant frequencies of 293, 2,274, 3,186, and 3,755 Hz; bandwidths of 80, 90, 150, and $350 \mathrm{~Hz}$, respectively; and a fundamental frequency of $120 \mathrm{~Hz}$ (high-flat tone, Tone $1 \mathrm{in}$ Mandarin). The syllables differed only in the point of maximum rise in amplitude during the initial $130 \mathrm{~ms}$ frication portion. The affricate consonant had a fast amplitude rise, with maximum amplitude occurring at $30 \mathrm{~ms}$; the fricative consonant had a slower amplitude rise time, with 
Language input and brain responses in bilingual and monolingual infants maximum amplitude occurring at $100 \mathrm{~ms}$. Tokens were equalized in RMS amplitude and played to infants at a comfortable listening level of 67 dBA (Kuhl et al., 2005, 2008; Kuhl, Tsao, \& Liu, 2003; Tsao, Liu, \& Kuhl, 2006).

Design

A classic oddball paradigm was used to collect the ERPs. This paradigm consists in delivering infrequent stimuli (physically Deviant) within a repetitive homogeneous stimulus sequence (Standard stimulus). The Standard sounds occurred with a probability of 0.85 (850 stimulus repetitions) and the Deviant sounds occurred with a probability of 0.15 (150 stimulus repetitions). Two rules governed stimuli presentation: 1) Deviant sounds could not occur consecutively, and 2) at least three Standard sounds were presented between Deviant sounds. The time between the offset of a stimulus and the onset of the next stimulus (inter stimulus interval) was $705 \mathrm{~ms}$. The odd-ball paradigm used in the present investigation does not control for infants' attention as reported by Shafer et al. $(2011,2012)$. There were no breaks during stimulation and therefore, deviant sounds never occurred in the final position.

At the end of the classic odd-ball paradigm, the Deviant sound was presented 200 times for use as a Control-Deviant to which the Deviant response was compared during analysis. This approach is used to minimize the so called "MMN N1-contamination" (King, McGee, Rubel, Nicol, \& Kraus, 1995; Kraus et al., 1992; 1995; McGee, Kraus, \& Nicol, 1997). The latency of the N1 closely approximates that of the MMN response (i.e., $100 \mathrm{~ms}$ after stimulus onset), and its amplitude is sensitive to feature changes in the signal. Therefore, acoustic differences between standard and deviant result in amplitude change at the level of the N1 and MMN. The MMN N1- 
Language input and brain responses in bilingual and monolingual infants contamination can be reduced by comparing the deviant stimulus when presented "as a deviant" to the deviant stimulus when presented "as a standard" because the sounds to be compared are acoustically identical (for an extensive review on MMN N1-contamination see May \& Tiitinen, 2010).

\section{Electrophysiological procedure}

Infants were awake and tested inside a sound treated room. The child sat on the parent's lap. In front of them, a research assistant entertained the child with quiet toys while a muted movie played on a TV behind the assistant. The research assistant and the parent wore headphones with masking music during testing. The electroencephalogram (EEG) was recorded using electro-caps (ECI, Inc.) incorporating 32 pre-inserted tin inverting electrodes. The EEG was referenced to the left mastoid from Fp1, Fpz, Fp2, F7, F3, Fz, F4, F8, FC5, FC1, FC2, FC6, T3, C3, Cz, C4, T4, CP5, CP1, CP2, CP6, T5, P3, Pz, P4, T6, O1 Oz, O2, and RM in the International 10/20 System. Infant eye-blinks were monitored by recording the electrooculogram from 1 infraorbital electrode placed on the infant's left cheek. The EEG data was collected in DC mode and it was re-referenced off-line to the right mastoid to obtain a more balanced reference distribution. The electroencephalogram was recorded using NeuroScan SynAmps RT amplifiers (24 bit A/D converter) using Scan4.5 software. A 1 ms trigger was time-locked to the presentation of each stimulus to accomplish the ERP averaging process ( $\mathrm{Stim}^{2}$ Neuroscan Compumedics).

Electrode impedances were kept below $5 \mathrm{~K} \Omega$. EEG segments with electrical activity $+/$ $150 \mathrm{mV}$ at any electrode site were omitted from the final average. EEG segments of $700 \mathrm{~ms}$ with 
Language input and brain responses in bilingual and monolingual infants a pre-stimulus baseline time of $100 \mathrm{~ms}$ were selected and averaged offline to obtain the ERPs. Baseline correction was performed in relationship to the pre-stimulus time. The ERP wave forms were band-pass filtered from 1 to $40 \mathrm{~Hz}(12 \mathrm{~dB} \text { roll off })^{2}$ using the zero phase shift mode function in NeuroScan Edit 4.5. The ERP waveforms in figures 2 and 3 were band-pass filtered from 1 to $30 \mathrm{~Hz}$ (12dB roll off) for illustration purposes.

In the present investigation we report only the left frontal regions (F7, F3, FC5, FC1, and C3), since previous research has shown that lateral-anterior regions show a strong relationship between phonetic discrimination and the amount of language input in bilingual infants (GarciaSierra et al., 2011; Kuhl et al., 2008) and have been also used to index degree of language commitment in monolingual infants (Kuhl et al., 2014).

Control-Deviant and Deviant ERP amplitude analyses. The amplitudes for the ControlDeviant and Deviant responses were calculated by averaging the voltage values from two ERP time windows: $150-350 \mathrm{~ms}$ and 350-550 ms. The mean-amplitude of the Deviant ERP response was compared with the mean-amplitude of the Control-Deviant ERP response. The Deviant $v s$. Control-Deviant comparison in the 150-350 ms time-window range will be referred as pMMR while the comparison in the 350-550 ms time-window range will be referred as nMMR.

The left frontal electrode region was computed by averaging the mean amplitude values for each electrode site for the Control-Deviant and Deviant. Difference waveforms were calculated independently for each speech contrast by subtracting the Control-Deviant ERP from the Deviant ERP (Deviant minus Control-Deviant). 
Language input and brain responses in bilingual and monolingual infants

Difference waveforms. In order to explore the relationship between the pMMR and the nMMR response associated with speech perception, we calculated the difference waveform between Control-Deviant and Deviant ERPs for all speech contrasts. Specifically, the ControlDeviant ERP response was subtracted from the Deviant ERP response for each of the three speech contrasts. For each difference waveform two time-windows of interest were evaluated; 150-350 ms after stimulus onset associated with the pMMR and 350-550 ms after stimulus onset associated with the nMMR response. The amplitude from the pMMR and the nMMR were compared as a function of language input for planned comparisons.

Correlations between brain measures and language input. Infants' difference waveforms from left-anterior electrodes were correlated with caregivers' word counts to investigate the relationships among language input, pMMR, and nMMR (i.e., 150-350 ms and 350-550 ms after stimulus onset; respectively). For monolingual infants, pMMRs and nMMRs were independently correlated with caregivers' word count in English. For bilingual infants the pMMR and nMMR responses for the English and Spanish contrasts were independently correlated with caregivers' word count in English and Spanish, respectively. For bilingual infants the sum of caregivers' word count in both languages was also correlated with infants' pMMRs and nMMRs for English and Spanish. The pMMR and nMMR brain responses associated with the Chinese contrast were independently correlated with caregivers' word count in English for monolinguals and in English and Spanish for bilingual infants.

Amplitude differentiation between pMMR and nMMR. Researchers have reported that the latency of the nMMR response decreases with increasing age and therefore the pMMR can 
Language input and brain responses in bilingual and monolingual infants partially or fully overlap with the nMMR (He, Hotson, \& Trainor, 2007; Morr et al., 2002). In the present investigation we explore whether this pattern of brain activation can be seen in bilingual and monolingual infants as a function of language input and speech contrasts type (native vs non-native). In order to accomplish this aim, the pMMR difference wave amplitude (obtained by subtracting deviant minus control-deviant in the $150-350 \mathrm{~ms}$ time window) is statistically compared to the nMMR difference wave amplitude (obtained by subtracting the deviant and control-deviant in the 350-550 ms time window).

The number of ERP trials accepted. ERPs for the 3 speech contrasts were recorded in three separate sessions, and the number of ERP Control-Deviant and Deviant trials accepted differed across stimulus condition (Table 2), yielding variable signal-to-noise ratios which, in turn, could bias the ERP statistical analyses. Consequently, the number of Control-Deviant and Deviant trials accepted for ERP averaging was compared in a 3 (Language: English, Spanish, and Chinese speech contrasts) by 2 (ERP type: Control-Deviant and Deviant) repeated measures ANOVA using Group (monolingual vs. bilingual) as between subjects factor. GreenhouseGeisser epsilon (ع) was used for non-sphericity correction. Our interest was specific to the Group $x$ ERP $x$ Language interaction, which was found to be non-significant, $F(1.95,66.28)=.72: p=$ $.50, \eta_{\mathrm{p}}{ }^{2}=.021$, indicating any significant mean-amplitude difference between Control-Deviant and Deviant is unlikely to be caused by differences in the number of trails accepted across language conditions.

\section{Results}


Language input and brain responses in bilingual and monolingual infants

The goal of the present study was to assess neural commitment as a function of language input. In order to accomplish this goal, ERP mean-amplitudes were obtained in response to Control-Deviant and Deviant stimuli in two time windows: 150-350 ms after stimulus onset (i.e., pMMR), and 350-550 ms after stimulus onset (i.e., nMMR). This analysis was completed for each of the three speech contrasts (i.e., Spanish, English, and Chinese). Deviant and ControlDeviant mean-amplitudes were analyzed as a function of language input groups based on a median split of parental word-count in English and in Spanish (i.e., high and low).

Initial analyses employing participant age (i.e., 11 months and 14 months) as a between subjects factor did not yield significant main effects or interactions for age. Analyses reported below were collapsed across participants' age. Also preliminary analysis comparing both hemispheres did not show significant differences. The analyses reported below are specific to the left frontal electrodes as described in the methods section.

We first compared Deviant and Control-Deviant amplitudes independently for pMMR and nMMR as a function of language input. Specifically, Repeated measure ANOVAs examining ERP type (Deviant ERP vs. Control-Deviant ERP) as a within subjects factor and language input group (high and low) as a between subjects factor were completed independently for English, Spanish and Chinese speech contrasts in the pMMR (150-350 ms) and the nMMR (350-550 ms) measurement windows for monolinguals and bilinguals. The focus of the analyses was ERP type by language input group interactions, with planned comparisons of ERP type for each English language input group. Second, we correlated the difference waveforms independently for each time window with amount of language input and third, we compared the difference wave form 
Language input and brain responses in bilingual and monolingual infants amplitudes for the pMMR and nMMR (amplitude differentiation) as a function of language input.

\section{ERP Response as a Function of English Language Input in Monolinguals}

Native English speech contrast. The ERP type by English language input group interaction was not significant at the pMMR time window, $F(1,16)=1.47, p=.24, \eta_{\mathrm{p}}{ }^{2}=0.08$. However, the planned comparison of ERP type was significant for the low English input group, $F(1,16)=4.52, p=.049, \eta_{\mathrm{p}}^{2}=0.22$, with the Deviant significantly more positive (Mean = $6.86 \mu \mathrm{V}, S E=1.61)$ than the Control-Deviant (Mean $=4.07 \mu \mathrm{V}, S E=1.05)$ (Figure 1, left bottom panel and Figure 2 panel B). The ERP type by language input group interaction was significant for the nMMR, $F(1,16)=6.40, p=.02, \eta_{\mathrm{p}}{ }^{2}=0.29$. Furthermore, the planned comparison of ERP type was significant for the high English language input group, $F(1,16)=4.80, p=.043, \eta_{\mathrm{p}}{ }^{2}=$ 0.23 ), with the Deviant significantly more negative (Mean $=-3.22 \mu \mathrm{V}, S E=1.32)$ than the Control-Deviant $($ Mean $=.36 \mu \mathrm{V}, S E=1.31)($ Figure 1, right bottom panel and Figure 2 panel B $)$.

Non-native Spanish speech contrast. The ERP type by language input group interaction was not significant at the pMMR time window, $\left.F(1,16)=.90, p=.356, \eta_{\mathrm{p}}{ }^{2}=0.05\right)$, and planned comparisons of ERP type were not significant for either the high or low English language input groups (Figure 1, left middle panel and Figure 2 panel A). The ERP type by language input group interaction was also non-significant at the nMMR time window, $F(1,16)=1.09, p=.31$,

$\eta_{\mathrm{p}}{ }^{2}=0.06$, and planned comparisons of ERP type for both high and low English language input groups were also not significant (Figure 1, right middle panel and Figure 2 panel A). 
Language input and brain responses in bilingual and monolingual infants

Non-native Chinese speech contrast. Main effects for ERP type were significant $(F(1,16)$ $=19.00, p=.004, \eta_{\mathrm{p}}{ }^{2}=.5$ ) with the deviant significantly more positive (Mean= $\left.5.52 \mu \mathrm{V}, S E=.69\right)$ than the control deviant (Mean $=2.14 \mu \mathrm{V}, S E=.63)$. The ERP type by language input group interaction was not significant at the pMMR time window, $\left.F(1,16)=.248, p=.63, \eta_{\mathrm{p}}{ }^{2}=0.02\right)$, and the planned comparisons of ERP type were significant for both the low, $F(1,16)=11.79, p$ $\left.=.003, \eta_{\mathrm{p}}{ }^{2}=0.42\right)$ and high English language input groups, $F(1,16)=7.45, p=.015, \eta_{\mathrm{p}}{ }^{2}=0.32$ ). Specifically, the Deviant was significantly more positive than the Control-Deviant in both the low English language input group (Deviant Mean $=5.51 \mu \mathrm{V}, S E=.98$, and Control-Deviant Mean $=1.73 \mu \mathrm{V}, S E=1.73)$ and the high English language input group (Deviant Mean $=5.55 \mu \mathrm{V}, S E=$ .90$, Control-Deviant Mean $=2.55 \mu \mathrm{V}, S E=.90)($ Figure 1 left top panel and Figure 2 panel A). The ERP type by language input group interaction was not significant at the nMMR time window, $\left.F(1,16)=.86, p=.37, \eta_{\mathrm{p}}{ }^{2}=0.05\right)$, as were planned comparisons of ERP type for both high and low English language input groups (Figure 1, right top panel and Figure 2 panel A).

Correlations between MMRs and amount of language input. Monolingual caregivers' word count was not significantly correlated with infants' pMMRs $(r(16)=-.392, p=.108)$, but were significantly and negatively correlated with infants' nMMR $(r(16)=-.551, p=.018)$. For the native language, the more words monolingual infants hear in their everyday lives, the more robust nMMR (Figure 2 panel B). This relationship was not found with the brain responses associated with the non-native speech contrasts (see Table 3 for more details).

ERP Responses as a Function of English Language Input in Bilinguals 
Language input and brain responses in bilingual and monolingual infants

Native English speech contrast. The ERP type by English language input group interaction was significant in the pMMR time window, $\left.F(1,16)=6.14, p=.025, \eta_{\mathrm{p}}{ }^{2}=0.28\right)$. The planned comparison of ERP type was significant only for the high English language input group, $\left.F(1,16)=7.30, p=.016, \eta_{\mathrm{p}}^{2}=0.31\right)$, with the Deviant significantly more positive (Mean = $5.44 \mu \mathrm{V}, S E=1.30)$ than the Control-Deviant (Mean $=2.07 \mu \mathrm{V}, S E=1.11)$ (Figure 3, left bottom panel and Figure 5 panel B). The ERP type by English language input group interaction was not significant at the nMMR time window, $F(1,16)=1.19, p=.291, \eta_{\mathrm{p}}{ }^{2}=0.07$, and planned comparisons of ERP type were not significant for either the high or the low English language input group (Figure 3, right bottom panel and Figure 5 panel B).

Non-native Chinese speech contrast as a function of amount of English input. The ERP type by English language input group interaction was not significant at the pMMR time window, $\left.F(1,17)=.48, p=.49, \eta_{\mathrm{p}}{ }^{2}=0.03\right)$, and planned comparisons of ERP type were not significant for either the high or the low English language input group (Figure 3, left top panel and Figure 5 panel A). The ERP type by English language input group interaction was not significant at the nMMR time window, $\left.\mathrm{F}(1,17)=.13, p=.72, \eta_{\mathrm{p}}{ }^{2}=0.08\right)$, and planned comparisons of ERP type were not significant for either the high or the low English language input group (Figure 3, right top panel and Figure 5 panel A).

ERP Responses as a Function of Spanish Language Input in Bilinguals

Native Spanish speech contrast. Main effects for ERP type were significant $(F(1,17)=$ $16.37, p=.001, \eta_{\mathrm{p}}^{2}=.5$ ), with the deviant significantly more positive (Mean $=6.80 \mu \mathrm{V}, S E=.82$ ) than the control deviant (Mean $=4.70 \mu \mathrm{V}, S E=.94)$. The ERP type by Spanish language input 
Language input and brain responses in bilingual and monolingual infants group interaction was significant at the pMMR time window, $F(1,17)=6.71, p=.019 \eta_{\mathrm{p}}{ }^{2}=$ 0.28). The planned comparison of ERP type was significant only for the high $\underline{\text { Spanish language }}$ input group $\left(F(1,17)=20.92, p=.0001, \eta_{\mathrm{p}}{ }^{2}=0.55\right)$, with the Deviant significantly more positive $($ Mean $=8.89 \mu \mathrm{V}, S E=1.19)$ than the Control-Deviant $($ Mean $=5.46 \mu \mathrm{V}, S E=1.37)($ Figure 4, left bottom panel and Figure 5 panel B). The ERP type by Spanish language input group interaction was not significant at the nMMR time window, $F(1,17)=.025, p=.87, \eta_{\mathrm{p}}{ }^{2}=0.00$ ), and planned comparisons of ERP type were not significant for either the high or the low Spanish language input group (Figure 4, right bottom panel and Figure 5 panel B).

Non-native Chinese speech contrast as a function of amount of Spanish input. The ERP type by Spanish language input group interaction was not significant at the pMMR time window, $\left.F(1,17)=.66, p=.43, \eta_{\mathrm{p}}^{2}=0.04\right)$, and planned comparisons of ERP type were not significant for either the high or the low Spanish language input group (Figure 4, left top panel and Figure 5 panel A). The ERP type by Spanish language input group interaction was not significant at the nMMR time window, $\left.F(1,17)=.46, p=.51, \eta_{\mathrm{p}}{ }^{2}=0.03\right)$, and planned comparisons of ERP type were not significant for either the high or the low Spanish language input group (Figure 4, right top panel and Figure 5 panel A).

Correlations between MMRs and amount of language input. Bilinguals exhibited significant positive correlations between word count and pMMR in each of their native languages. Specifically, English language word count was significantly and positively correlated with the difference waveform amplitude of the English contrast pMMR, $r(16)=.569, p=.014$ ), and Spanish language word count was significantly and positively correlated with the difference 
Language input and brain responses in bilingual and monolingual infants waveform mean-amplitude of the Spanish contrast pMMR, $r(17)=.509, p=.026$ ). For each of their native languages, the more words bilingual infants hear in their everyday lives, the stronger the more robust pMMR (Figure 5). Correlations were not significant for nMMR in bilinguals' native languages (English and Spanish) or for either response to the non-native speech contrast (see more details in Table 4).

Further Analyses for Bilinguals

We explored whether hearing more words in any language would influence language processing in a specific language. We added the number of words used by caregivers in English and in Spanish and correlated the sum with the pMMR in English and in Spanish and the nMMR in English and in Spanish. None of the correlations were significant. pMMR / nMMR Amplitude Differentiation as a Function of Language Input

We examined the relationship between pMMR and nMMR (1) in response to native language contrasts as a function of language input, and (2) in response to non-native contrasts. In order to accomplish this goal, we compared the amplitude of the pMMR $v s$. the amplitude of the nMMR (Deviant minus Control-Deviant difference waveforms) for the 3 speech contrasts by mean of paired t-tests.

The top panel of Figure 6 shows brain responses to native speech sounds in monolinguals and bilinguals as a function of language input. Monolingual and bilingual infants with high language input in their native language(s) showed an amplitude differentiation between the pMMR and the nMMR response (see Table 1 for the number of participant in each group). The nMMR is significantly more negative than the pMMR for the English contrast in high language 
Language input and brain responses in bilingual and monolingual infants input group monolinguals, $t(8)=3.13, p=.014$, and in high English language group bilinguals, $t(7)=2.85, p=.025$; recall one bilingual did not have usable ERP data for the English contrast). Bilinguals showed the same pattern for the Spanish contrast, where the nMMR is significantly more negative than the pMMR in the high Spanish language input group, $t(8)=2.74, p=.026$ ). No significant differences were found in the groups with low amounts of language input.

The bottom panel of Figure 6 shows brain responses to non-native speech sounds in monolinguals and bilinguals. Note that correlations with language input are not relevant or represented in the figure. Monolinguals did not show an amplitude differentiation between the pMMR and nMMR for Spanish or Chinese non-native contrasts. In contrast to monolinguals, bilinguals did show a significant amplitude differentiation between the pMMR and nMMR for the Chinese non-native contrast: nMMR was significantly more negative than pMMR, $t(18)=$ $4.17, p=.001$.

\section{Discussion}

The present study investigated language commitment by means of brain responses in monolingual and bilingual infants using an innovative approach to characterize language input in natural settings as infants go about their everyday lives. Furthermore, we evaluated brain responses to both native and non-native speech sounds in both groups.

The primary focus of the present investigation was acquisition of speech sound representation in monolingual and bilingual infants. We postulated that the amount of language input infants receive from their caregivers is strongly related to specific patterns of brain activation in the infant. We evaluated 2 brain responses: the pMMR associated with attentional 
Language input and brain responses in bilingual and monolingual infants mechanisms associated with establishing specific perceptual routines (Shafer et al., 2012; Strange, 2011) and the nMMR associated with "neural commitment" to the native language (Kuhl et al., 2008). We also report the relationship between the pMMR and nMMR amplitudes as a way to explore the characteristics of the neural patterns associated with language commitment as a function of language input in monolinguals and bilinguals.

In general, our findings are consistent with the hypothesis that monolinguals are fully committed to their native language at the end of the first year of life (Kuhl et al., 1992; Moon, Lagercrantz, \& Kuhl, 2013; Werker \& Tees, 1984). However, the inclusion of language input data in the analysis revealed full commitment only in monolingual infants with high language input. In contrast, monolinguals with low language input showed a neural pattern similar to that observed in bilingual infants with high input in a specific language. The similar neural pattern in brain response observed in both monolingual infants with low language input and bilingual infants with high language input may be due to the fact that both groups received similar amounts of language-specific input in their everyday lives.

\section{Brain Responses to Native Speech Sounds in the Monolingual Infants}

We hypothesized that monolingual infants receiving low amounts of language input may not be committed to their native language due to reduced language experience, and therefore would exhibit pMMRs to their native speech sounds without nMMRs. On the other hand, monolingual infants with high amounts of language input were expected to show commitment to their native language in the form of nMMRs. Our results confirmed our expectations. Monolinguals from the low English language input group showed brain responses interpreted as 
Language input and brain responses in bilingual and monolingual infants representing attentional mechanisms that precede automatic speech perception (pMMR; Deviant more positive than Control-Deviant) while monolingual infants with high amounts of English input showed commitment to their native language in the form of a significant nMMRs (Deviant more negative than Control-Deviant). We also predicted significant correlations between infants' brain responses and the amount of language input received (as indicated by adult word count). The results showed a significant correlation between caregivers' word count and infants' nMMRs: high language input is associated with a more robust (i.e., negative) nMMR brain response, indicating stronger neural commitment to the native language. Monolingual infants receiving lesser amounts of language input in their everyday lives are still developing perceptual routines that will ultimately contribute to efficient speech perception (Shafer et al., 2012; Strange, 2011; Strange \& Shafer, 2008). We argue that infants receiving lesser amounts of language input will transition to full neural commitment later in life, consistent with previous findings of the emergence of nMMR as a function of age and language input (Cheour et al., 2001; Čeponienè et al., 2000; 2004; Kuhl et al., 2008; Kushnerenko et al., 2002; Garcia-Sierra et al., 2011; Gomes et al., 1999; Rivera-Gaxiola, Silva-Pereyra, et al., 2005; Rivera-Gaxiola, Klarman, et al., 2005; Morr et al., 2002; Shafer et al., 2000; Trainor et al., 2003).

The subtraction of the Control-Deviant response from the Deviant response (creating a difference waveform) allowed exploration of the relationship between the pMMR and nMMR as a function of language input and speech contrast. The amplitude differentiation was not significant for the 2 non-native speech contrasts (Spanish and Chinese). However, we found that monolingual infants in the high language input group showed significant differentiation between 
Language input and brain responses in bilingual and monolingual infants the pMMR and the nMMR difference wave amplitudes only in response to their native English speech sounds. The transition from pMMR to nMMR/MMN has been described as a function of age (Shafer, Yu, \& Datta, 2010; Shafer et al., 2011) but has rarely been evaluated in terms of the amount of language input (i.e., Garcia-Sierra et al., 2011). The results of the present investigation indicate that infants who receive high amounts of language input show nMMRs earlier in development than infants who receive lower amounts of language input. Nevertheless, infants in the low language input group are expected to continue to develop their specific perceptual routines as a function of language input and cortical development and, with time, these perceptual routines will result in language commitment (Kuhl et al., 2008; Shafer et al., 2012; Strange, 2011).

Brain Responses to Non-Native Speech Sounds in the Monolingual Infants

In this investigation we used 2 non-native speech contrasts as controls in English monolingual infants (Spanish and Chinese). We postulated that neural patterns in response to non-native speech sounds are dependent on the frequency of occurrence of similar native language speech sounds and by the amount of language input. For example, stop consonants are quite common in the English language and the acoustic properties of the Spanish contrast represent a single phonemic category in the English language (Spanish /da-ta/ are both perceived as English /da/). With this in mind, we hypothesized that monolingual infants would perceive the Spanish contrast as two variants of English /da/ (single category assimilation see; Best, 1992). Our results confirmed our expectations. Specifically, monolingual infants did not show amplitude difference between Deviant and Control-Deviant ERP responses overall or as a 
Language input and brain responses in bilingual and monolingual infants function of language input, suggesting the Spanish contrast was perceived as the same speech sound.

The Chinese contrast, on the other hand, is not part of the English phonology (alveolopalatal affricate and alveolo-palatal fricative; $/ \mathrm{tc}^{\mathrm{h}} \mathrm{i}-\mathrm{ci} /$, respectively) and it was hypothesized that monolingual infants would perceptually assimilate into the closest English phonemic category (affricate postalveolar or fricative palatal; [t \& J], respectively; see Mines et al., 1978). Note that in contrast with stop consonants, the English fricative and affricate consonants are infrequent in the English language. Hence infants have had little experience with these sounds and may be still developing specific perceptual routines (Shafer et al., 2012; Strange, 2011). For these reasons, the Chinese contrast would be difficult to assimilate into English phonology and pMMRs with no observable nMMRs were expected. Our results confirmed our expectations. We found similar significant differences in pMMRs in both the high and low English language input groups for the non-native Chinese contrast with Deviant-ERPs significantly more positive than ControlDeviants in both English language input groups. In addition, correlations between language input and the pMMRs or nMMRs were not significant. This indicates that the significant differences between Deviant and Control-Deviant are not related to amount of language input and therefore are better explained in terms of the difficulty of the discrimination task in the absence of specific perceptual routines (Hisagi et al., 2010; Shafer et al., 2011; Shafer et al., 2012; Strange \& Shafer, 2008). We postulate that as monolingual infants gain more experience in the English language they will assimilate the Chinese contrast to the closest English phonemic category and, as in the case of the Spanish contrast, a positive-MMR would not be expected. 
Language input and brain responses in bilingual and monolingual infants

Finally, monolingual infants did not show a pMMR / nMMR differentiation for the

Chinese contrast. The lack of an amplitude relationship between the pMMR and the nMMR indicates that the Chinese contrast is not exhibiting neural patterns associated with native language commitment. Interestingly, the Chinese contrast resulted in a pattern of brain activation that was very different from the Spanish contrast. Specifically, the perception of the Chinese contrast resulted in an overall positivity for the pMMR and nMMR, whereas the Spanish contrast resulted in more negative brain responses. We postulate the Chinese contrast required more attentional process than the Spanish contrast since infants had not yet formed perceptual routines for the low frequency English affricate / fricative. Therefore, the pMMR reflected enhanced attentional process for sounds that are more difficult to discriminate (Cheng et al., 2015; Kuo et al., 2014; Lee et al., 2012; Hisagi et al., 2010).

\section{Brain Responses to Native Speech Sounds in the Bilingual Infants}

Understanding the relationship between neural commitment and language input in bilingual participants is more challenging. Although we recruited families who identify themselves as Spanish-English bilinguals, few bilinguals were exposed to 50\% Spanish and 50\% English. This is consistent with recent studies that demonstrated that although simultaneous bilinguals are exposed to two languages in the home, one of these languages is dominant in terms of quantity (e.g., Hoff et al., 2012; Song, Tamis-LeMonda, Yoshikawa, Kahana-Kalman, \& Wu, 2011; Ramírez-Esparza, Garcia-Sierra, \& Kuhl, in press).

Our results demonstrate that more language input in a given language is associated with advances in the process of neural commitment to that language in bilinguals. We postulated that 
Language input and brain responses in bilingual and monolingual infants bilingual infants with low amounts of language input would show pMMRs with no observable nMMRs, while bilingual infants receiving high amounts of language input would only show nMMRs. In contrast, our results demonstrated that bilinguals with high language input to their native language are not yet fully committed. We observed significant pMMRs (but not nMMRs) for both the high English and high Spanish language input groups. Therefore, infants with relatively high English or Spanish input are not fully committed to their native language, consistent with findings showing that the pMMR likely represents attentional mechanisms guiding speech perception (Shafer et al., 2012; Strange, 2011). Bilinguals with low input to English or to Spanish, in the other hand, showed no significant pMMRs or nMMRs suggesting no clear pattern in language commitment. These different patterns of neural activation were confirmed by a significant positive correlation between specific amounts of language input and the size of the pMMR. The correlation indicated a relation in which the more language input infants receive, the more robust the pMMR response. These correlations were language specific and the total word count in English and Spanish did not correlate with the brain responses of interest in either language.

Recall that monolingual infants in the low language input group and bilingual infants in the high English language input group showed similar word counts. Therefore, the present study shows that monolingual and bilingual infants with similar amounts of language input show parallel neural patterns associated with phonetic learning. Previous research has shown that monolingual and bilingual infants have different timelines for neural commitment to the native language(s) (Garcia-Sierra et al., 2011). The present study demonstrates the differential timeline 
Language input and brain responses in bilingual and monolingual infants for neural commitment is a function of language input. Furthermore, we extend the findings of Garcia-Sierra et al. (2011) by demonstrating that bilingual and monolinguals infants with similar amounts of language input show similar neural trajectories associated with language commitment. Therefore, it is likely that monolinguals with low input and bilinguals with high input will transition to full neural commitment later in life, exhibiting similar timing in language learning.

Regarding the pMMR / nMMR amplitude differentiation for the English and Spanish contrasts, we found that bilinguals showed a pattern of relationships between amount of language input and pMMR / nMMR amplitude differentiation similar to that observed in monolingual infants. Specifically, bilinguals in the high language input groups show a significant amplitude differentiation between pMMR and nMMR for the relevant native language contrasts (i.e., English and Spanish). In contrast, bilinguals in the low English and Spanish input group showed no amplitude differentiation between pMMR and nMMR. These results indicate that the consideration of two brain measures (i.e., pMMR / nMMR amplitude differentiation) may be more sensitive to language commitment than individual ERP responses (i.e., Deviant ERP vs. Control-Deviant ERP in specific time windows).

\section{Brain Responses to Non-Native Speech Sounds in the Bilingual Infants}

To our knowledge, this is the first study that has included a non-native speech contrast as a control for bilingual participants. As anticipated, and as observed in monolinguals, brain responses to non-native speech contrasts did not differ with the overall amount of language input in bilinguals; therefore, overall language input is not considered in this discussion. We expected 
Language input and brain responses in bilingual and monolingual infants that the perception of the Chinese speech contrast in bilingual infants would differ from that of monolingual infants. Since bilingual infants are developing phonological representations for two languages, they are able to assimilate the Chinese contrast into the phonetic space of either of their native languages (i.e., English or Spanish phonetic space) (Antoniou et al., 2012; Best, 1992). Our results confirmed this expectation, revealing a different pattern of brain activation for the Chinese contrast in bilinguals and monolinguals. Bilinguals did not show a significant amplitude difference between Deviant and Control-Deviant for the pMMR or nMMR, while monolinguals showed significant pMMRs for the Chinese contrast with no significant nMMRs. We interpret the lack of a significant amplitude difference between Deviant and Control-Deviant as evidence that, as hypothesized, bilinguals are able to represent the Chinese contrast in terms of a single Spanish or English phonetic category.

As noted above, monolingual infants may not have sufficient experience to develop phonemic representations for the English affricate postalveolar and fricative palatal speech sounds ([t \& \& J]; respectively) that are most similar to the Chinese contrast. Consequently, the acoustic properties of the Chinese contrast were processed without specific perceptual routines and not perceptually assimilated into their native English phonology. In contrast, bilinguals are developing phonemic representation with more complex input. English has two possible categories to perceptually represent the Chinese contrast (i.e., $[t \& \&]$ ) while Spanish has only one phonetic category to perceptually assimilate the Chinese contrast (Spanish postalveolar affricate $[\mathfrak{t}])$. In other words, Spanish $[\mathfrak{t}]$ is phonetically unique and therefore mastered earlier than English $\left[\mathfrak{t} \& \int\right]$ with equivalent amounts of relevant language input. Therefore, the acoustic 
Language input and brain responses in bilingual and monolingual infants properties of the Chinese alveolo-palatal affricate (/t $\left.{ }^{\mathrm{h}} \mathrm{i} /\right)$ and alveolo-palatal fricative (/6i/) were likely mapped on to the Spanish postalveolar affricate (i.e., [t]]) as indicated by no amplitude difference between Deviant and Control-Deviant ERPs. A similar pattern was observed in monolingual infants for the Spanish contrast in which monolingual infants likely assimilated the Spanish contrast/da-ta/ as a single English phonetic sound (i.e., /da/). In other words, bilingual infants revealed a pattern of brain responses to the non-native Chinese contrast that was very similar to that seen in monolingual infants in response to the non-native Spanish contrast.

We did not anticipate our finding of a significant pMMR / nMMR amplitude differentiation without significant amplitude differences between Deviant and Control-Deviant for the Chinese contrast in bilingual infants. In the case of monolingual infants, all measures were non-significant for the non-native Spanish contrast (i.e., amplitude differences between Deviant and Control-Deviant in both time windows and amplitude differentiation between pMMR and nMMR), suggesting the assimilation of two different sounds onto a single phonemic category. In the case of bilinguals, we postulate that bilingual infants with more Spanish than English input accounted for the group level amplitude differentiation between the pMMR and nMMR for the Chinese contrast. Recall that the Spanish phonology can assimilate both speech sounds of the Chinese contrast into a single phonetic category ([t] $]$ ), while the English phonology can assimilate the speech sounds of the Chinese contrast into two categories ([t $\left.\& \int\right]$ ). Therefore, differences in the relative amounts of language input in English and Spanish may affect assimilation of the non-native Chinese contrast. Still, more research needs to be done to 
Language input and brain responses in bilingual and monolingual infants better understand whether different amounts of language input in bilinguals result in different patterns of brain activation to non-native speech sounds.

Overall, these results indicate that phonological representations of non-native speech sounds in bilingual infants are dependent on the existent phonetic similarities between their native languages and the amount of input in each of their native languages. Future studies should include a speech contrast that is non-native and also has acoustic properties that are similar in terms of frequency in the native languages of the monolingual or bilingual sample. In fact, we are now collecting brain responses associated with a Hindi stop consonant contrast from English monolingual and English-Spanish bilingual infants to further elucidate the relationship of language input and neural commitment for non-native speech sounds.

\section{pMMR / nMMR Amplitude Differentiation}

In the present investigation we assessed the relationship between the pMMR and nMMR as a function of language input. We postulate that the amplitude relationship between the pMMR and nMMR is a more integrative measure that is a better representation of the time course of language commitment than the independent exploration of these individual brain responses. However, the reader should note that evaluation of the relative contribution of the pMMR and nMMR components to a significant pMMR / nMMR amplitude differentiation provides insight into underlying mechanisms in language commitment. We propose that the pMMR may indicate 2 different phases in language commitment depending on the presence of a significant pMMR / nMMR amplitude differentiation: (1) an observable pMMR that is not 
Language input and brain responses in bilingual and monolingual infants accompanied with a significant $\mathrm{pMMR} / \mathrm{nMMR}$ amplitude differentiation suggests that infants still rely on attentional mechanisms to develop selective perceptual routines that will allow for efficient and automatic detection of speech sound contrasts with additional language input (Shafer et al., 2012; Strange, 2011); (2) a pMMR accompanied with a significant pMMR / nMMR amplitude differentiation suggests the presence of a specific perceptual routine that guides speech categorization. Therefore, the interpretation of the pMMR differs as a function of the pMMR / nMMR amplitude differentiation. In one configuration, infants are sensitive to any acoustic variation without showing language commitment (pMMR with no MMR / nMMR differentiation), while in the other infants show sensitivity to the phonetic detail of their native language(s) and therefore language commitment (Kuhl et al., 2008) (pMMR with MMR / nMMR differentiation). Our results confirm this interpretation, demonstrating that significant correlations between caregivers' word count and both pMMRs and nMMRs were observed most often in the high language input groups that showed pMMR / nMMR amplitude differentiations. As mentioned above, we are collecting data for a Hindi speech contrast from English monolingual and English-Spanish bilingual infants to further elucidate the relationship between pMMR and pMMR / nMMR amplitude differentiation by controlling for frequency of occurrence across native and non-native contrasts.

\section{Limitations and Future Directions}

Our approach codes only a small fraction of the complete recording, and intervals were chosen based on highest adult word count in order to maximize intervals with language input. This approach does not allow us to capture language input in a continuous way. Furthermore, 
Language input and brain responses in bilingual and monolingual infants this investigation does not include speech directed to the child from other adults or children. Although the method is not an ideal assessment of language exposure, it does have advantages compared to other methods of assessment (e.g., short recordings in the home/laboratory or selfreports). For example, our method is non-obtrusive (see Mehl \& Holleran, 2007) and it captures natural everyday language that is not available in shorter video-recorded interactions. We also use the LENA software to locate segments distributed across the dataset that are suitable for estimating language input. Importantly, our method avoid biases since caregivers can overestimate or underestimate their usage of English or Spanish in self-reports (e.g., Heine, Lehman, Peng, \& Greenholtz, 2002; Heine \& Renshaw, 2002; Ramírez-Esparza, Gosling, \& Pennebaker, 2008). Finally, our method can be used to assess language input in monolingual populations without falling in the shortcomings of ceiling effects that are commonly found in self-reports.

It is important to note that our measure of language input was significantly lower for bilinguals than monolinguals. This may be related to differences in socioeconomic status (SES) or to specific cultural differences across samples. Since SES of bilingual families was lower than monolingual families, and SES has been shown to be related to language input to children, it is possible that the lower word count for bilingual caregivers is related lower SES (e.g., Hoff, 2003). In addition, since language from other adults was not transcribed due to limits of informed consent, word count might have been underestimated in bilinguals due to cultural characteristics (e.g., Ramírez-Esparza, García-Sierra, \& Kuhl, in press). For example, Latinos spend more time engaged in group interactions, whereas European-Americans spend more time 
Language input and brain responses in bilingual and monolingual infants alone (Ramírez-Esparza, Mehl, Alvarez-Bermúdez, \& Pennebaker, 2009). Therefore, it is possible that the Latino bilingual infants in the current study were more likely to be exposed to polyadic situations and multi-party conversations due to their cultural background (Lieven, 1994).

Another important limitation of this study is the sample size. Dividing monolinguals and bilinguals into low and high language exposure groups reduced the number of participants in each cell. Although the analyses were significant, it is important for future work to replicate these findings in a larger sample to improve the effect size (Funder et al., 2014). Furthermore, a larger sample, will allow control for socio-demographic variables, such as SES, ethnic background, education, the number of members living in the household. A follow-up study, controlling for these socio-demographic variables would evaluate the role of language input on speech perception above and beyond the cultural characteristics of the families.

\section{Conclusion}

The present investigation evaluated neural commitment as a function of language input by measuring two types of ERP brain responses; one that is associated with an attentional mechanism preceding automatic processing in the development of speech perception (pMMR) and another that is associated with neural commitment (nMMR). Monolingual infants with high amounts of language input showed a neural pattern associated with commitment to their native language. Monolingual and bilingual infants with comparable amounts of language input (i.e., monolinguals with low language input and bilinguals with high language input in one of their native languages) showed a neural pattern associated with the attentional mechanism preceding 
Language input and brain responses in bilingual and monolingual infants automatic processing of speech sounds. The neural patterns associated with the non-native speech contrasts suggested that both groups utilize their native phonologies to assimilate the foreign sounds. However, bilingual infants seemed to assimilate the non-native Chinese speech contrast with greater ease, perhaps due to having 2 native phonologies. The patterns of neural commitment associated with different degrees of language input in monolingual and bilingual infants were more similar when the relationship between the pMMR / nMMR was evaluated. The pMMR / nMMR amplitude differentiation for the native speech sounds showed similar patterns for monolingual and bilingual infants with high language input and with low language input. It is proposed that the pMMR / nMMR amplitude differentiation is a sensitive measure to assess language commitment. However, non-native speech perception in dual language learners is a complex area requiring additional study.

\section{Acknowledgments}

The research reported here was supported by a National Science Foundation Science of Learning Program grant to the LIFE Center (SBE-0354453). The authors thank Denise Padden for her valuable input regarding the manuscript and Pat Stock, Julia Mizrahi and Lindsay Klarman for their help in collecting the data.

\section{Footnotes}

${ }^{1}$ As a reliability test for word count selection, we used mothers' perspective recordings. As part of this study, infants' mothers also wore a digital recorder, and this data was also 
Language input and brain responses in bilingual and monolingual infants transcribed as part of another study, using the same methods presented on this paper.

Specifically, 20030 -sec intervals were selected and the speech of both the mothers and fathers in the selected intervals were transcribed. This comparative sample of intervals allows reliability assessment. We correlated the number of words transcribed from the infants' perspective with the number of words transcribed from the mothers' perspective for monolingual and bilinguals. The results showed strong and significant pearson correlations for both monolinguals $(\mathrm{r}=.75, \mathrm{p}<$ $.001, \mathrm{~N}=17$, data was not available for 1 monolingual mother) and bilinguals in English $(\mathrm{r}=.84$, $\mathrm{p}<.001, \mathrm{~N}=19)$ and in Spanish $(\mathrm{r}=.72, \mathrm{p}=.001, \mathrm{~N}=19)$. These results show that the pattern of word counts is consistent in intervals that are independently selected from the infants' and mothers' recordings, indicating that our approach is reliable.

${ }^{2}$ Sabri and Campbell (2002) recorded MMRs in awake and asleep infants with different filter settings; low-pass filters of 24, 12 or $6 \mathrm{~Hz}$, and high-pass filters at either 1, 2, 3 or $4 \mathrm{~Hz}$. Applying a low-pass filter down to $12 \mathrm{~Hz}$ had minimal impact on the waking or sleeping MMR amplitude. In the same manner, applying high-pass filters up to $3 \mathrm{~Hz}$ has minimal impact in the MMR amplitude. The high-pass filter of $4 \mathrm{~Hz}$ markedly attenuated the amplitude of the waking MMN and thus is not recommended.

\section{References}

Antoniou, M., Tyler, M. D., \& Best, C. T. (2012). Two ways to listen: Do L2-dominant bilinguals perceive stop voicing according to language mode? Journal of Phonetics, 40(4), 582-594.

Aslin, R. N., D. B. Pisoni, et al. (1981). Discrimination of voice onset time by human infants: New findings and implications for the effects of early experience. Child Development, $52,1135-1145$.

Best, C. T. (1992). Emergence of Language-Specific Constraints in Perception of Non-native Speech: A Window on Early Phonological Development. In S. d. S. Boysson-Bardies, 
Language input and brain responses in bilingual and monolingual infants

Peter Jusczyk, Peter McNeilage and John Morton (Eds.), Neurocognition: Speech and Face Processing in the First Year of Life (pp. 289-304). Netherlands: Kluwer Academic Publishers.

Byers-Heinlein, K., Burns, T. C., \& Werker, J. F. (2010). The Roots of Bilingualism in Newborns. Psychological Science, 21(3), 343-348. doi:10.1177/0956797609360758

Čeponienè, R., Lepistö, T., Soininen, M., Aronen, E., Alku, P., \& Näätänen, R. (2004). Eventrelated potentials associated with sound discrimination versus novelty detection in children. Psychophysiology, 41, 130-141.

Čeponiene, R., Yaguchi, K., Shestakova, A., Alku, P., Suominen, K., \& Näätänen, R. (2002). Sound complexity and 'speechness' effects on pre-attentive auditory discrimination in children. International Journal of Psychophysiology, 43, 199-211.

Cheng, Y. Y., Wu, H. C., Tzeng, Y. L., Yang, M. T., Zhao, L. L., \& Lee, C. Y. (2013). The Development of Mismatch Responses to Mandarin Lexical Tones in Early Infancy. Developmental Neuropsychology, 38, 281-300.

Cheng, Y.-Y., Wu, H.-C., Tzeng, Y.-L., Yang, M.-T., Zhao, L.-L., \& Lee, C.-Y. (2015). Featurespecific transition from positive mismatch response to mismatch negativity in early infancy: Mismatch responses to vowels and initial consonants. International Journal of Psychophysiology, 96(2), 84-94.

Cheour, M., Alho, K., Ceponiene, R., Reinikainen, K., Sainio, K., Pohjavuori, M., . . Näätänen , R. (1998). Maturation of mismatch negativity in infants. International Journal of Psychophysiology, 29(2), 217-226.

Cheour, M., Alho, K., Sainio, K., Reinikainen, K., Renlund, M., Aaltonen, O., . . Näätänen, R. (1997). The mismatch negativity to changes in speech sounds at the age of three months. Developmental Neuropsychology, 13(2), 167-174.

Cheour, M., Ceponiene, R., Lehtokoski, A., Luuk, A., Allik, J., Alho, K., \& Näätänen, R. (1998). Development of language-specific phoneme representations in the infant brain. Nature Neuroscience, 1, 351-353.

Cheour, M., H.T. Leppänen, P., \& Kraus, N. (2000). Mismatch negativity (MMN) as a tool for investigating auditory discrimination and sensory memory in infants and children. Clinical Neurophysiology, 111(1), 4-16.

Cheour-Luhtanen, M., Alho, K., Kujala, T., Sainio, K., Reinikainen, K., Renlund, M., . . . Näätänen, R. (1995). Mismatch negativity indicates vowel discrimination in newborns. Hearing Research, 82(1), 53-58.

Curtin, S., Byers-Heinlein, K., \& Werker, J. F. (2011). Bilingual beginnings as a lens for theory development: PRIMIR in focus. Journal of Phonetics, 39(4), 492-504. doi:10.1016/j.wocn.2010.12.002

Dehaene-Lambertz, G., \& Baillet, S. (1998). A phonological representation in the infant brain. Neuroreport, 9(8), 1885-1888.

Dehaene-Lambertz, G., \& Dehaene, S. (1994). Speed and cerebral correlates of syllable discrimination in infants. Nature, 370(6487), 292-295.

Eilers, R. E., Gavin, W., \& Wilson, W. R. (1979). "Linguistic Experience and Phonemic Perception in Infancy: A Crosslinguistic Study." Child Development 50, 14-18. 
Language input and brain responses in bilingual and monolingual infants

Eilers, R. E., Wilson, W. R., \& Moore, J. M. (1977)"Developmental-Changes in SpeechDiscrimination in Infants." Journal of Speech and Hearing Research, 20, 766-780.

Ferjan Ramírez, N., Ramírez, R. R., Clarke, M., Taulu, S., \& Kuhl, P. K. (2016). Speech discrimination in 11-month-old bilingual and monolingual infants: a magnetoencephalography study. Developmental Science, n/a-n/a. doi:10.1111/desc.12427

Friederici, A. D., Friedrich, M., \& Christophe, A. (2007). Brain responses in 4-month-old infants are already language specific. Current Biology, 17(14), 1208-1211. doi:DOI 10.1016/j.cub.2007.06.011

Friedrich, M., Weber, C., \& Friederici, A. D. (2004). Electrophysiological evidence for delayed mismatch response in infants at-risk for specific language impairment. Psychophysiology, 41(5), 772-782. doi:10.1111/j.1469-8986.2004.00202.x

Froyen, D. J. W., Bonte, M. L., van Atteveldt, N., \& Blomert, L. (2008). The Long Road to Automation: Neurocognitive Development of Letter-Speech Sound Processing. Journal of Cognitive Neuroscience, 21(3), 567-580.

Funder, D. C., Levine, J. M., Mackie, D. M., Mork, C. C., Sansone, C., Vazire, S., and West, S. G. (2014). Improving the dependability of research in Personality and Social Psychology: Recommendations for research and educational practice. Personality and Social Psychology Review, 18, 3-12.

Garcia-Sierra, A., N. Ramírez-Esparza, Silva-Pereyra, J., Siard, J., \& Champlin, C. A. (2012). Assessing the double phonemic representation in bilingual speakers of Spanish and English: An electrophysiological study. Brain and Language 121, 194-205.

Garcia-Sierra, A., R. L. Diehl, \& Champlin, C. A. (2009). Testing the double phonemic boundary in bilinguals. Speech Communication, 51, 369-378.

Garcia-Sierra, A., Rivera-Gaxiola, M., Percaccio, C. R., Conboy, B. T., Romo, H., Klarman, L., . . Kuhl, P. K. (2011). Bilingual language learning: An ERP study relating early brain responses to speech, language input, and later word production. Journal of Phonetics, 39, 546-557.

Gervain, J., \& Werker, J. F. (2013). Prosody cues word order in 7-month-old bilingual infants. Nature Communications, 4. doi:10.1038/ncomms2430

Gomes, H., Molholm, S., Ritter, W., Kurtzberg, D., Cowan, N., \& Vaughan, H. G. (2000). Mismatch negativity in children and adults, and effects of an attended task. Psychophysiology, 37(6), 807-816. doi:10.1111/1469-8986.3760807

Gomes, H., Sussman, E., Ritter, W., Kurtzberg, D., Cowan, N., \& Vaughan, H. G., Jr. (1999). Electrophysiological evidence of developmental changes in the duration of auditory sensory memory. Developmental Psychology, 35(1), 294-302. doi:10.1037/00121649.35.1.294

He, C., Hotson, L., \& Trainor, L. J. (2007). Mismatch Responses to Pitch Changes in Early Infancy. Journal of Cognitive Neuroscience, 19(5), 878-892. doi:doi:10.1162/jocn.2007.19.5.878

Heine, S. H., Lehman, D. R., Peng, K., \& Greenholtz, J. (2002). What's wrong with crosscultural comparisons of subjective likert scales?: The Reference-Group Effect. Journal of Personality and Social Psychology, 82, 903-918. doi: 10.1037/0022-3514.82.6.903 
Language input and brain responses in bilingual and monolingual infants

Hisagi, M., Shafer, V. L., Strange, W., \& Sussman, E. S. (2010). Perception of a Japanese vowel length contrast by Japanese and American English listeners: Behavioral and electrophysiological measures. Brain Research, 1360, 89-105. doi:http://dx.doi.org/10.1016/j.brainres.2010.08.092

Hoff, E. (2003). The specificity of environmental influence: socioeconomic status affects early vocabulary development via maternal speech. Child Development, 74, 1368-1878. doi: 10.1111/1467-8624.00612

Hoff, E., Core, C., Place, S., Rumiche, R., Señor, M., \& Parra, M. (2012). Dual language exposure and early bilingual development. Journal of Child Language, 39, 1-27.

Hollingshead, A. B. (2011). "Four Factor Index of Social Status." Yale Journal of Sociology, 8, 21-52.

Jusczyk, P. W. (2000). The discovery of spoken language. Massachusetts: MIT.

Jusczyk, P. W., Cutler, A., \& Redanz, N. J. (1993). Infants' preference for the predominant stress patterns of English words. Child Development, 64, 675-687.

Jusczyk, P. W., Friederici, A. D., Wessels, J. M. I., Svenkerud, V. Y., \& Jusczyk, A. M. (1993). Infants' sensitivity to the sound patterns of native language words. Journal of Memory and Language, 32, 402-420.

King, C., McGee, T., Rubel, E. W., Nicol, T., \& Kraus, N. (1995). Acoustic features and acoustic changes are represented by different central pathways. Hearing Research, 85(1-2), 45-52.

Klatt, D. H. (1980). Software for a cascade/parallel formant synthesizer. Journal of the Acoustical Society of America, 67, 971-990.

Kraus, N., McGee, T., Carrel, T., D., King, C., Tremblay, K., \& Nicol, T. (1995). Central Auditory System Plasticity Associated with Speech Discrimination Training. Journal of Cognitive Neuroscience, 7(1), 25-32.

Kraus, N., McGee, T., Sharma, A., Carrell, T., \& Nicol, T. (1992). Mismatch negativity eventrelated potential elicited by speech stimuli. Ear Hear, 13(3), 158-164.

Krizman, J., Skoe, E., Marian, V., \& Kraus, N. (2014). Bilingualism increases neural response consistency and attentional control: Evidence for sensory and cognitive coupling. Brain and Language, 128(1), 34-40. doi:http://dx.doi.org/10.1016/j.bandl.2013.11.006

Kuhl, P. K., Conboy, B. T., Coffey-Corina, S., Padden, D., Rivera-Gaxiola, M., \& Nelson, T. (2008). Phonetic learning as a pathway to language: new data and native language magnet theory expanded (NLM-e). Philosophical Transactions of the Royal Society BBiological Sciences, 363(1493), 979-1000.

Kuhl, P. K., Conboy, B. T., Padden, D., Nelson, T., \& Pruitt, J. (2005). Early Speech Perception and Later Language Development: Implications for the "Critical Period". Language Learning \& Development, 1(3/4), 237-264.

Kuhl, P. K., Ramírez, R. R., Bosseler, A., Lin, J.-F. L., \& Imada, T. (2014). Infants' brain responses to speech suggest Analysis by Synthesis. Proceedings of the National Academy of Sciences, 111(31), 11238-11245.

Kuhl, P. K., Stevens, E., Hayashi, A., Deguchi, T., Kiritani, S., \& Iverson, P. (2006). Infants show a facilitation effect for native language phonetic perception between 6 and 12 months. Developmental Science, 9(2), F13-F21. 
Language input and brain responses in bilingual and monolingual infants

Kuhl, P. K., Tsao, F.-M., \& Liu, H.-M. (2003). Foreign-language experience in infancy: Effects of short-term exposure and social interaction on phonetic learning. Proceedings of the National Academy of Science, 100, 9096-9101.

Kuhl, P. K., Williams, K. A., Lacerda, F., Stevens, K. N., \& Lindblom, B. (1992). Linguistic experience alters phonetic perception in infants by six- months of age. Science, 255, 606608.

Kuo, Y.-c., Lee, C.-Y., Chen, M.-C., Liu, T.-L., \& Cheng, S.-k. (2014). The impact of spectral resolution on the mismatch response to Mandarin Chinese tones: An ERP study of cochlear implant simulations. Clinical Neurophysiology, 125(8), 1568-1575.

Kushnerenko, E., Ceponiene, R., Balan, P., Fellman, V., Huotilainen, M., \& Naatanen, R. (2002). Maturation of the auditory event-related potentials during the first year of life. Neuroreport, 13(1), 47-51.

Lee, C.-Y., Yen, H.-l., Yeh, P.-w., Lin, W.-H., Cheng, Y.-Y., Tzeng, Y.-L., \& Wu, H.-C. (2012). Mismatch responses to lexical tone, initial consonant, and vowel in Mandarin-speaking preschoolers. Neuropsychologia, 50(14), 3228-3239. doi:http://dx.doi.org/10.1016/j.neuropsychologia.2012.08.025

Leppänen, P. H. T., Eklund, K. M., \& Lyytinen, H. (1997). Event-related brain potentials to change in rapidly presented acoustic stimuli in newborns. Developmental Neuropsychology, 13(2), 175-204. doi:10.1080/87565649709540677

Lieven, E. V. M. (1994). Crosslinguistic and cross cultural aspects of language addressed to children. In C. Gallaway \& B. J. Richards (Eds.), Input and interaction in language acquisition (pp. 74-106). Cambridge: Cambridge University Press. doi: $10.1017 /$ cbo9780511620690.005

Liu, H.-M., Chen, Y., \& Tsao, F.-M. (2014). Developmental Changes in Mismatch Responses to Mandarin Consonants and Lexical Tones from Early to Middle Childhood. Plos One, 9(4), e95587. doi:10.1371/journal.pone.0095587

Luck, J. S. (2014). An Introduction to the Event-Related Potential Technique. Cambridge Massachusetts, The MIT Press.

Maurer, U., Bucher, K., Brem, S., \& Brandeis, D. (2003). Development of the automatic mismatch response: from frontal positivity in kindergarten children to the mismatch negativity. Clinical Neurophysiology, 114(5), 808-817. doi:http://dx.doi.org/10.1016/S1388-2457(03)00032-4

May, P. J. C., \& Tiitinen, H. (2010). Mismatch negativity (MMN), the deviance-elicited auditory deflection, explained. Psychophysiology, 47(1), 66-122. doi:10.1111/j.14698986.2009.00856.x

McGee, T., Kraus, N., \& Nicol, T. (1997). Is it really a mismatch negativity? An assessment of methods for determining response validity in individual subjects. Electroencephalography and Clinical Neurophysiology/Evoked Potentials Section, 104(4), 359-368. doi:http://dx.doi.org/10.1016/S0168-5597(97)00024-5

Mehl, M. R., \& Holleran, S. E. (2007). An empirical analysis of the obtrusiveness of and participants' compliance with the Electronically Activated Recorder (EAR). European Journal of Psychological Assessment, 23, 248-257. doi: 10.1027/1015-5759.23.4.248 
Language input and brain responses in bilingual and monolingual infants

Mines, M. A., Hanson, B. F., \& Shoup, J. E. (1978). Frequency of occurrence of phonemes in conversational English. Language and Speech, 21, 221-245.

Moon, C., Lagercrantz, H., \& Kuhl, P. K. (2013). Language experienced in utero affects vowel perception after birth: a two-country study. Acta Paediatrica, 102, 156-160.

Morr, M. L., Shafer, V. L., Kreuzer, J. A., \& Kurtzberg, D. (2002). Maturation of Mismatch Negativity in Typically Developing Infants and Preschool Children. Ear \& Hearing, 23(2), 118-136.

Näätänen, R. (1986). A classification of N2 kinds of ERP-components. In Cerebral psychophysiology: Studies in event related potentials, Eds. W.C.McCallum, R. Zappoli and F. Denoth. Electroencephalography \& Clinical Neurophysiology, Suppl 38., 169172.

Näätänen, R. (1990). The Role of Attention in Auditory Information-Processing as Revealed by Event-Related Potentials and Other Brain Measures of Cognitive Function. Behavioral and Brain Sciences, 13(2), 201-232.

Näätänen, R. (1992). Attention and Brain Function. Hillsdale, New Jersey: Lawrence Erlbaum Associates, Publishers.

Näätänen, R., \& Michie, P. T. (1979). Early Selective-Attention Effects on the Evoked-Potential - a Critical-Review and Reinterpretation. Biological Psychology, 8, 81-136.

Näätänen, R., Gaillard, A. W. K., \& Mantysalo, S. (1978). Early selective attention effect on evoked potential reinterpreted. Acta Poycholoica, 42, 313-329.

Näätänen, R., Lehtokoski, A., Lennes, M., Cheour, M., Huotilainen, M., Iivonen, A., . . Alho, K. (1997). Language-specific phoneme representations revealed by electric and magnetic brain responses. Nature, 385, 432-434.

Näätänen, R., Simpson, M., \& Loveless, N. E. (1982). Stimulus deviance and evoked potentials. Biological Psychology, 14, 53-98.

Osterhout, L., Bersick, M., \& McLaughlin, J. (1999). ERPS as tools for investigating human language. International Journal of Psychophysiology, 33, 41-42.

Ramírez-Esparza, N., Garcia-Sierra A., \& Kuhl, K. P. (2014). Look who's talking: Speech style and social context in language input to infants is linked to concurrent and future speech development. Developmental Science, 17, 880-891.

Ramírez-Esparza, N., Garcia-Sierra A., \& Kuhl, K. P. (in press). The impact of early social interactions on later language development in Spanish-English bilingual infants. Child Development.

Ramírez-Esparza, N., Gosling, S. D., \& Pennebaker, J. W. (2008). Paradox lost: Unraveling the puzzle of Simpatía. Journal of Cross-Cultural Psychology, 39, 703-715. doi: $10.1177 / 0022022108323786$

Ramírez-Esparza, N., Mehl, M. R., Alvarez-Bermúdez, J. \& Pennebaker, J. W. (2009). Are Mexicans more or less sociable than Americans? Insights from a naturalistic observation study. Journal of Research in Personality, 43, 1-7. doi: 10.1016/j.jrp.2008.09.002

Rivera-Gaxiola, M., Klarman, L., Garcia-Sierra, A., \& Kuhl, P. K. (2005). Neural patterns to speech and vocabulary growth in American infants. Neuroreport, 16, 495-498. 
Language input and brain responses in bilingual and monolingual infants

Rivera-Gaxiola, M., Silva-Pereyra, J., \& Kuhl, P. K. (2005). Brain potentials to native and nonnative speech contrasts in 7- and 11-month-old American infants. Developmental Science, 8(2), 162-172.

Sabri, M., \& Campbell, K. B. (2002). The effects of digital filtering on mismatch negativity in wakefulness and slow-wave sleep. J Sleep Res, 11(2), 123-127.

Sebastián-Gallés, N., Albareda-Castellot, B., Weikum, W. M., \& Werker, J. F. (2012). A Bilingual Advantage in Visual Language Discrimination in Infancy. Psychological Science, 23(9), 994-999. doi:10.1177/0956797612436817

Shafer, V. L., Morr, M. L., Kreuzer, J. A., \& Kurtzberg, D. (2000). Maturation of mismatch negativity in school-age children. Ear \& Hearing, 21(3), 242-251.

Shafer, V. L., Yu, Y. H., \& Datta, H. (2010). Maturation of speech discrimination in 4- to 7-yrold children as indexed by event-related potential mismatch responses. Ear \& Hearing, 31(6), 735-745. doi:10.1097/AUD.0b013e3181e5d1a7

Shafer, V. L., Yu, Y. H., \& Datta, H. (2011). The development of English vowel perception in monolingual and bilingual infants: Neurophysiological correlates. Journal of Phonetics, 39, 527-545.

Shafer, V. L., Yu, Y. H., \& Garrido-Nag, K. (2012). Neural mismatch indices of vowel discrimination in monolingually and bilingually exposed infants: Does attention matter? Neuroscience Letters, 526(1), 10-14. doi:http://dx.doi.org/10.1016/j.neulet.2012.07.064

Shtyrov, Y., \& Pulvermüller, F. (2007). Language in the mismatch negativity design: Motivations, benefits, and prospects. Journal of Psychophysiology, 21, 176-187.

Shucard, J. L., \& Shucard, D. W. (1990). Auditory evoked potentials and hand preference in 6month-old infants: Possible gender-related differences in cerebral organization. Developmental Psychology, 26(6), 923-930. doi:10.1037/0012-1649.26.6.923

Song, L., Tamis-LeMonda, S., Yoshikawa, H., Kahana-Kalman, R., \& Wu, I. (2012). Language experiences and vocabulary development in Dominican and Mexican infants across the first 2 years. Developmental Psychology, 48, 1106-1123.

Strange, W. (2011). Automatic selective perception (ASP) of first and second language speech: A working model. Journal of Phonetics, 39(4), 456-466. doi:http://dx.doi.org/10.1016/j.wocn.2010.09.001

Strange, W., \& Shafer, V. L. (2008). Speech perception in second language learners: The reeduction of selective perception. In J. G. Hansen-Edwards \& L. Z. M (Eds.), Phonology and second language acquisition (pp. 153-192). Amsterdam and Philadelphia: Johns Benjamins.

Tiitinen, H., May, P., Reinikainen, K., \& Näätänen, R. (1994). Attentive Novelty Detection in Humans Is Governed by Pre-Attentive Sensory Memory. Nature, 372, 90-92.

Trainor, L., McFadden, M., Hodgson, L., Darragh, L., Barlow, J., Matsos, L., \& Sonnadara, R. (2003). Changes in auditory cortex and the development of mismatch negativity between 2 and 6 months of age. International Journal of Psychophysiology, 51(1), 5-15.

Tsao, F. M., Liu, H. M., \& Kuhl, P. K. (2006). Perception of native and non-native affricatefricative contrasts: Cross-language tests on adults and infants. Journal of the Acoustical Society of America, 120(4), 2285-2294. 
Language input and brain responses in bilingual and monolingual infants

Weikum, W. M., Vouloumanos, A., Navarra, J., Soto-Faraco, S., Sebastián-Gallés, N., \& Werker, J. F. (2007). Visual Language Discrimination in Infancy. Science, 316(5828), 1159-1159. doi:10.1126/science. 1137686

Werker, J. (2012). Perceptual foundations of bilingual acquisition in infancy. In A. Kingstone \& M. B. Miller (Eds.), Year in Cognitive Neuroscience (Vol. 1251, pp. 50-61).

Werker, J. F., \& Hensch, T. K. (2015). Critical Periods in Speech Perception: New Directions. Annual Review of Psychology, 66(1), null. doi:doi:10.1146/annurev-psych-010814015104

Werker, J. F., \& Tees, R. C. (1984). Cross-Language Speech-Perception - Evidence for Perceptual Reorganization during the 1 st Year of Life. Infant Behavior \& Development, 7, 49-63.

Zachau, S., Rinker, T., Korner, B., Kohls, G., Maas, V., Hennighausen, K., \& Schecker, M. (2005). Extracting rules: early and late mismatch negativity to tone patterns. Neuroreport, 16(18), 2015-2019. 
Tables

Table 1. Means and standard deviations for language input groups

\begin{tabular}{ccccccc}
\hline \multicolumn{8}{c}{ Language Input } \\
\hline \multicolumn{4}{c}{ Monolinguals } & \multicolumn{4}{c}{ Bilinguals } \\
\hline \multicolumn{4}{c}{ English } & \multicolumn{2}{c}{ English } & \multicolumn{2}{c}{ Spanish } \\
\hline & High & Low & High & Low & High & Low \\
\hline N & 9 & 9 & 9 & 10 & 9 & 10 \\
Mean & $6,363.11$ & $4,546,77$ & $3,398.88$ & 805.40 & $3,127.77$ & $1,057.40$ \\
SD & 742.40 & 961.25 & $1,871.01$ & 310.52 & $1,135.46$ & 601.00 \\
\hline
\end{tabular}

Table 2. Average number of ERP trials accepted for Control-Deviant and Deviant stimuli.

\begin{tabular}{cccccccc}
\hline & \multicolumn{9}{c}{ Speech Contrast } \\
\hline \multirow{2}{*}{ GROUP } & \multicolumn{3}{c}{ English } & \multicolumn{2}{c}{ Spanish } & \multicolumn{2}{c}{ Chinese } \\
& & $\begin{array}{c}\text { Control- } \\
\text { Deviant }\end{array}$ & Deviant & $\begin{array}{c}\text { Control- } \\
\text { Deviant }\end{array}$ & Deviant & $\begin{array}{c}\text { Control- } \\
\text { Deviant }\end{array}$ & Deviant \\
\hline \multirow{2}{*}{ Monolingual } & Mean & 169 & 98 & 174 & 100 & 167 & 94 \\
& (SD) & $(55)$ & $(22)$ & $(48)$ & $(18)$ & $(44)$ & $(17)$ \\
\multirow{2}{*}{ Bilingual } & Mean & 156 & 99 & 172 & 108 & 167 & 99 \\
& (SD) & $(62)$ & $(19)$ & $(58)$ & $(13)$ & $(53)$ & $(16)$ \\
\hline
\end{tabular}

Table 3. Correlations between ERP mean-amplitude and native language word-count in monolingual infants

\begin{tabular}{cccccccc}
\hline & \multicolumn{8}{c}{ Speech Contrast } \\
\hline & \multicolumn{4}{c}{ English } & \multicolumn{2}{c}{ Spanish } & \multicolumn{2}{c}{ Chinese } \\
\hline Group & & pMMR & nMMR & pMMR & nMMR & pMMR & nMMR \\
\hline Monolingual & Pearson & -0.392 & $\mathbf{- 0 . 5 5 1}$ & 0.087 & -0.151 & -0.091 & -0.118 \\
caregivers' word & p-value & 0.108 & $\mathbf{0 . 0 1 8 *}$ & 0.732 & 0.551 & 0.718 & 0.64 \\
count & $\mathrm{N}$ & 18 & $\mathbf{1 8}$ & 18 & 18 & 18 & 18 \\
\hline
\end{tabular}


Table 4. Correlations between ERP mean-amplitude and native language word-count in bilingual infants

\begin{tabular}{ccccccccc}
\hline \multicolumn{1}{c}{ Speech Contrast } \\
\hline & \multicolumn{2}{c}{ English } & \multicolumn{2}{c}{ Spanish } & \multicolumn{2}{c}{ Chinese } \\
\hline Group & & pMMR & nMMR & pMMR & nMMR & pMMR & nMMR \\
\hline Bilinguals' & Pearson & $\mathbf{0 . 5 6 9}$ & 0.262 & -0.381 & -0.305 & -0.123 & -0.162 \\
English Word & p-value & $\mathbf{0 . 0 1 4 *}$ & 0.293 & .110 & .205 & 0.616 & 0.508 \\
Count & $\mathrm{N}$ & $\mathbf{1 8}$ & 18 & 19 & 19 & 19 & 19 \\
\hline Bilinguals' & Pearson & -0.392 & -.269 & $\mathbf{0 . 5 0 9}$ & 0.042 & -0.068 & -0.037 \\
Spanish Word & p-value & .108 & .281 & $\mathbf{0 . 0 2 6} *$ & 0.863 & 0.782 & 0.880 \\
Count & $\mathrm{N}$ & 18 & 18 & $\mathbf{1 9}$ & 19 & 19 & 19 \\
\hline
\end{tabular}


Figures

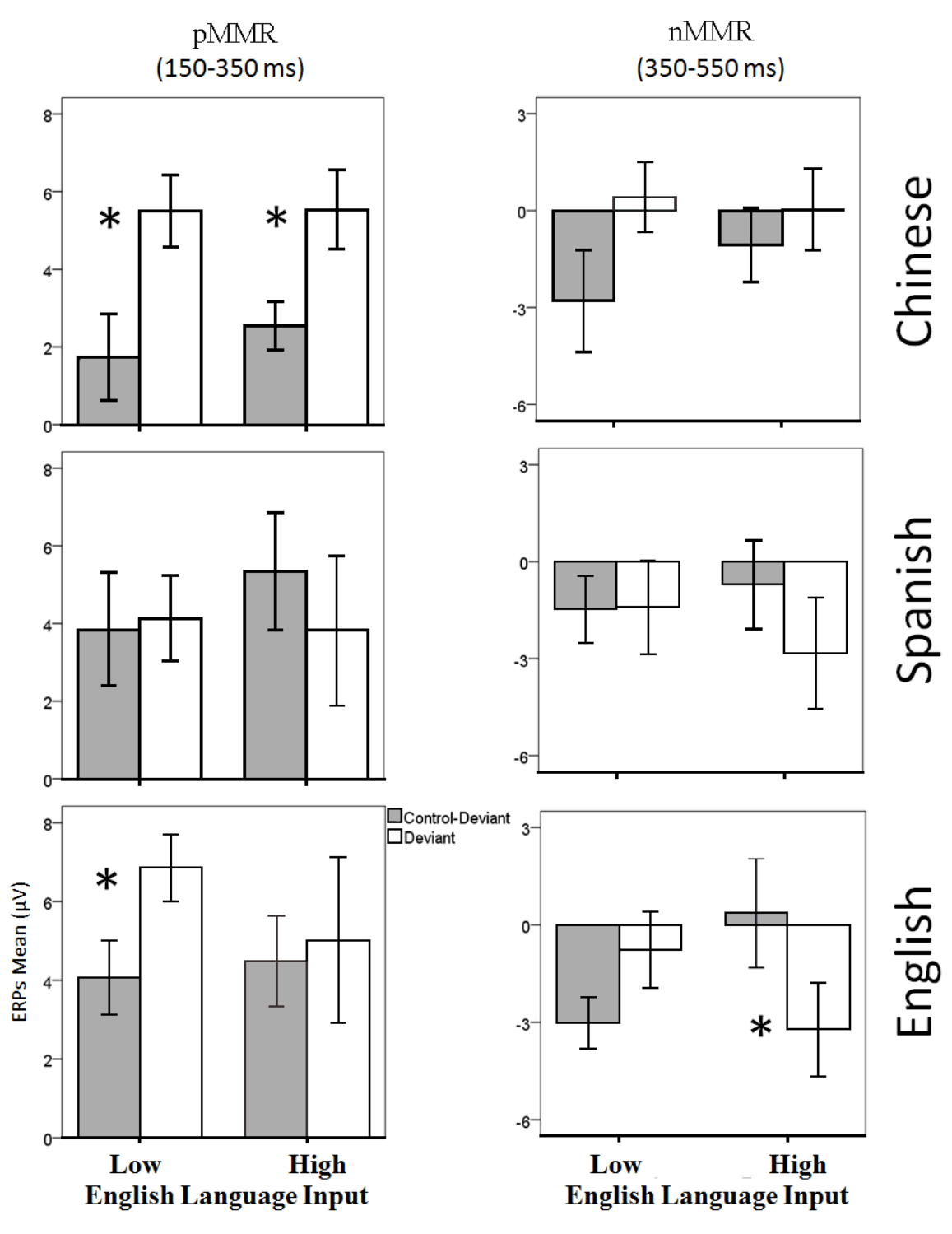

(Error bars denote +/- $1 \mathrm{SE}$ )

Figure 1. ERP mean-amplitudes for English, Spanish and Chinese speech contrasts in monolinguals as a function of English language input group. 


\section{Panel A: Non-Native speech discrimination}
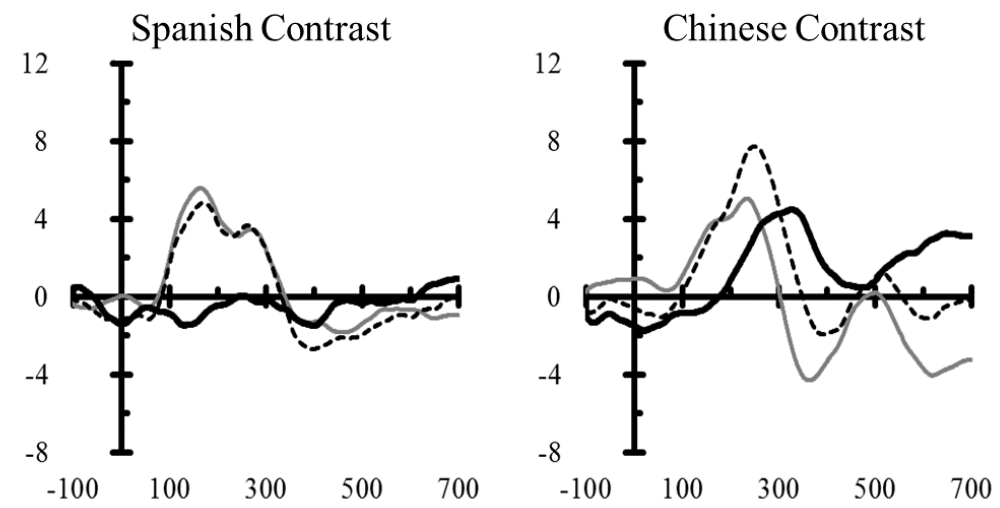

High \& Low English Language Input

\section{Panel B: Native Speech Discrimination}
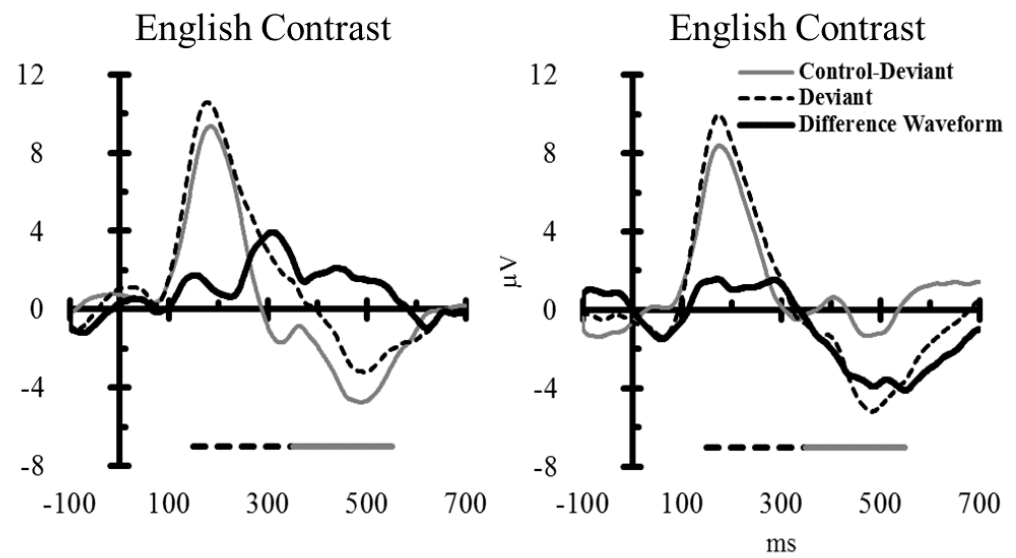

Low English Language Input

High English Language Input

Figure 2. ERPs to English, Spanish and Chinese speech contrasts in monolingual infants. Panel A shows non-native speech discrimination as a function of English language input. Panel B shows native speech discrimination as a function of English language input. Dotted lines in the bottom figures from Panel B show the measurement time windows for the pMMR (dotted line) and nMMR (straight line). 


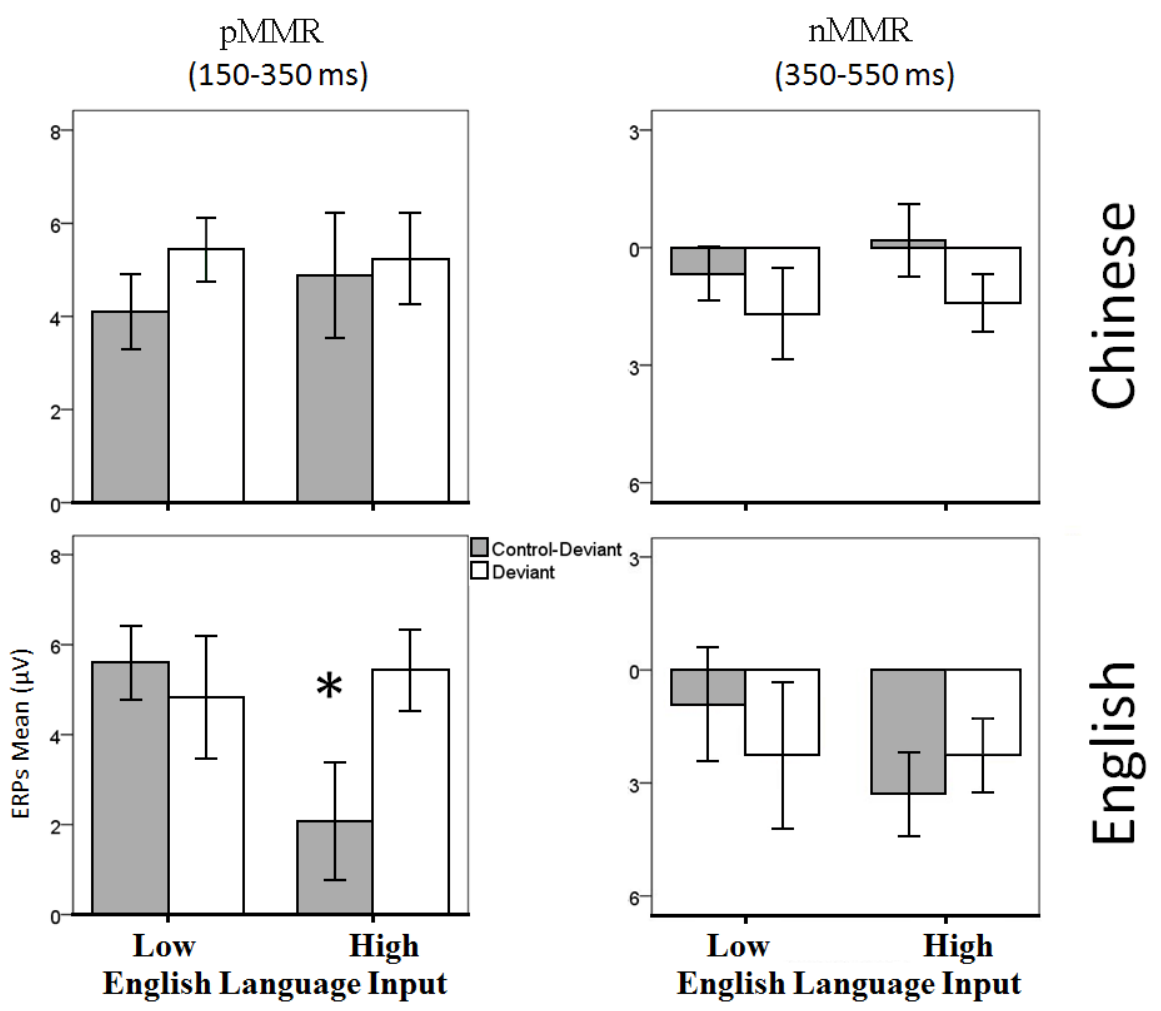

(Error bars denote +/- $1 \mathrm{SE}$ )

Figure 3. ERP mean-amplitudes for English and Chinese speech contrasts in bilinguals as a function of English language input group. 

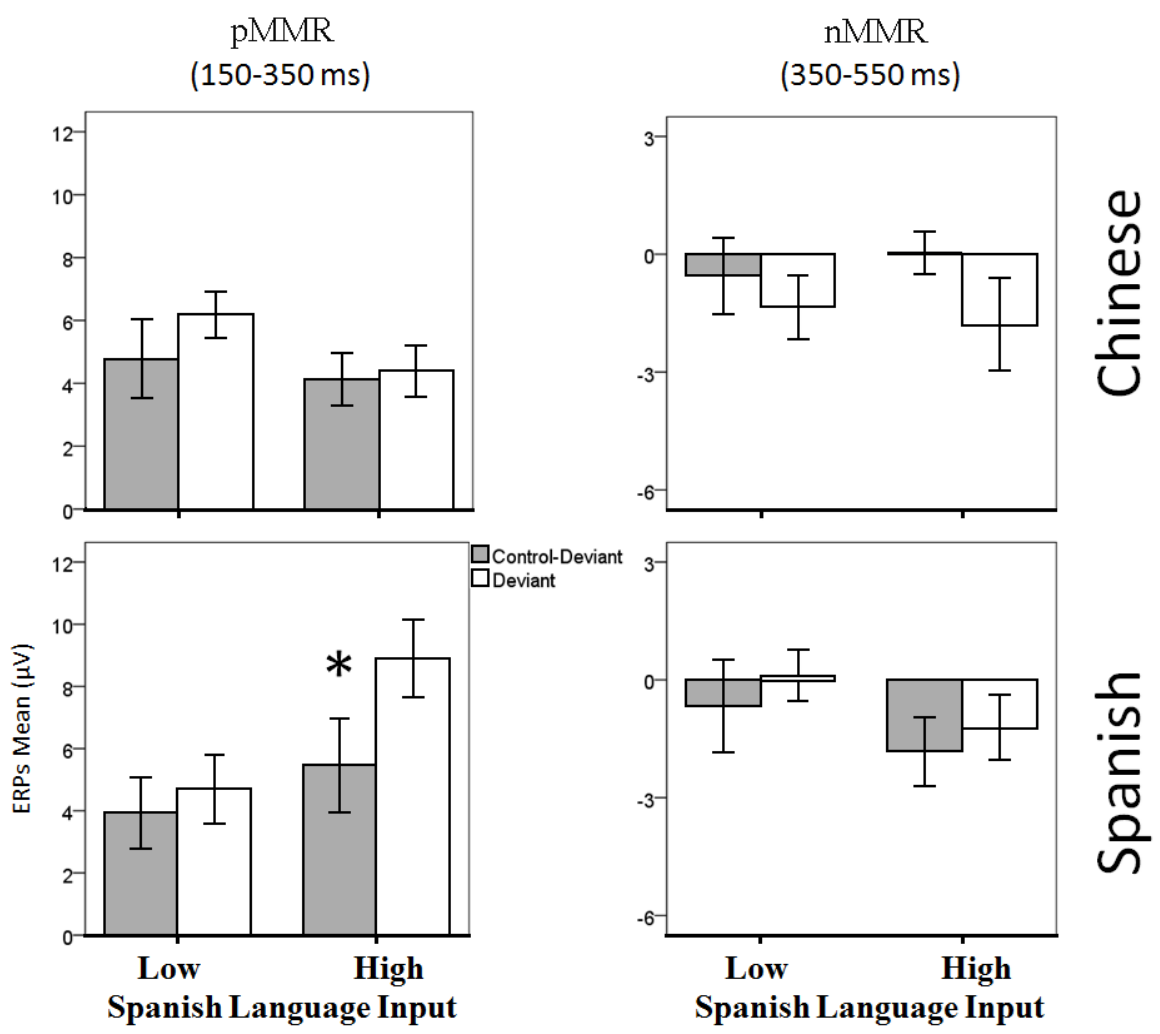

(Error bars denote +/- $1 \mathrm{SE}$ )

Figure 4. ERP mean-amplitudes for Spanish and Chinese speech contrasts in bilinguals as a function of Spanish language input group. 


\section{$\underline{\text { Panel A: Non-Native speech discrimination }}$}

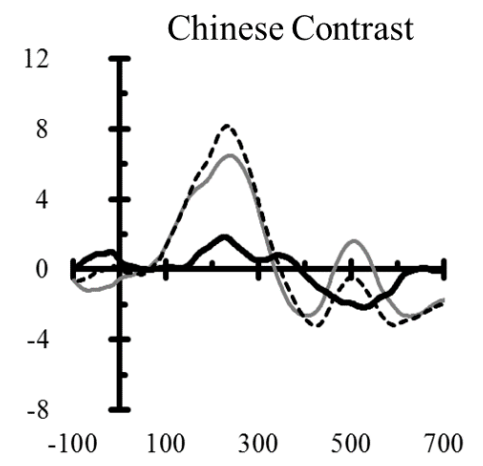

Low \& High English \& Spanish Language Input

\section{Panel B: Native Speech Discrimination}

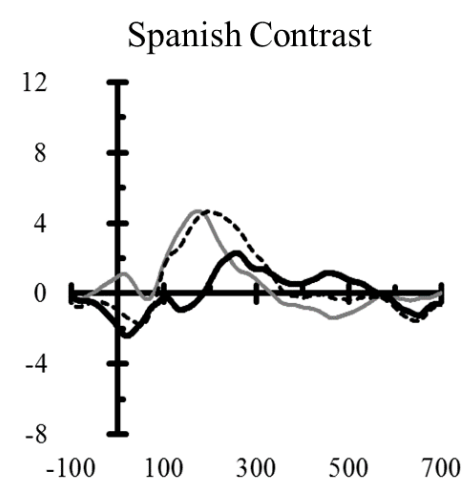

Low Spanish Language Input

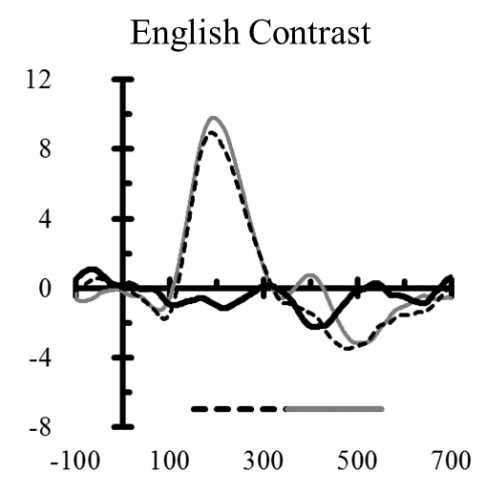

Low English Language Input

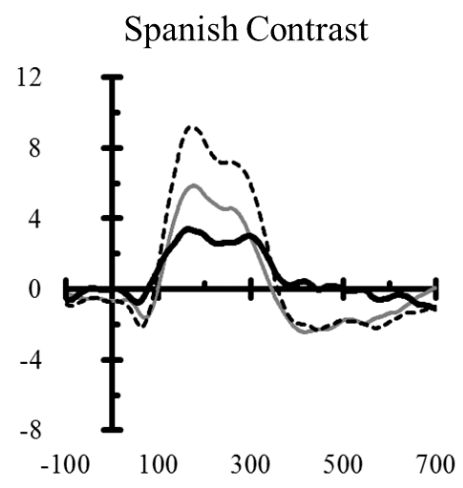

High Spanish Language Input

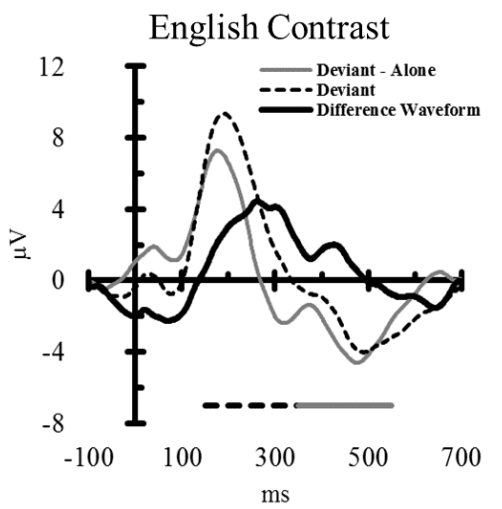

High English Language Input

Figure 5. ERPs to English, Spanish and Chinese speech contrasts in bilingual infants. Panel A shows native speech discrimination as a function of English language input and Spanish 
language input. Panel B shows non-native speech discrimination. Dotted lines in the bottom figures from Panel A show the measurement time windows for the pMMR (dotted line) and nMMR (straight line). 
Panel A: Native speech discrimination
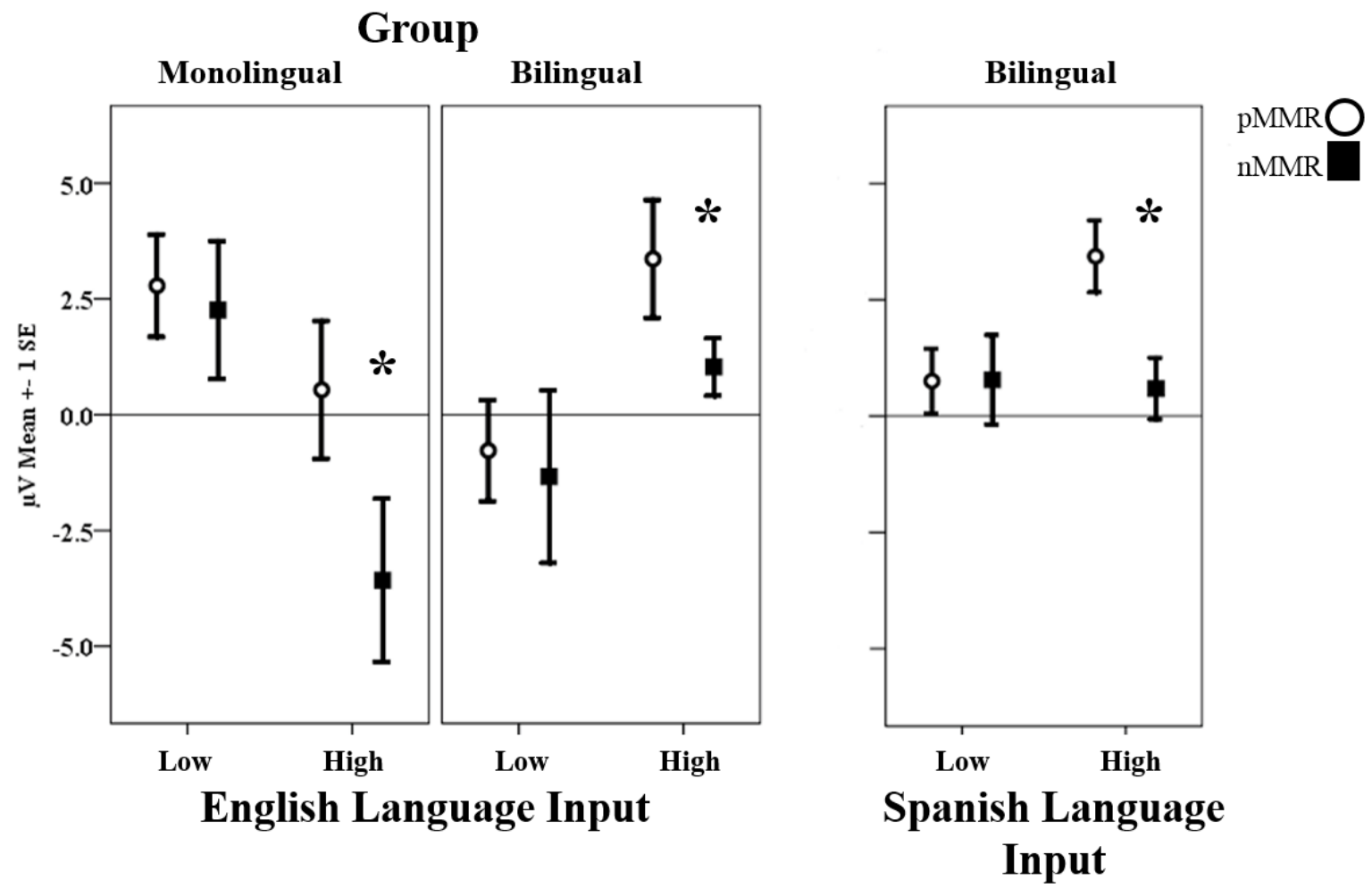
Panel B: Non-Native speech discrimination
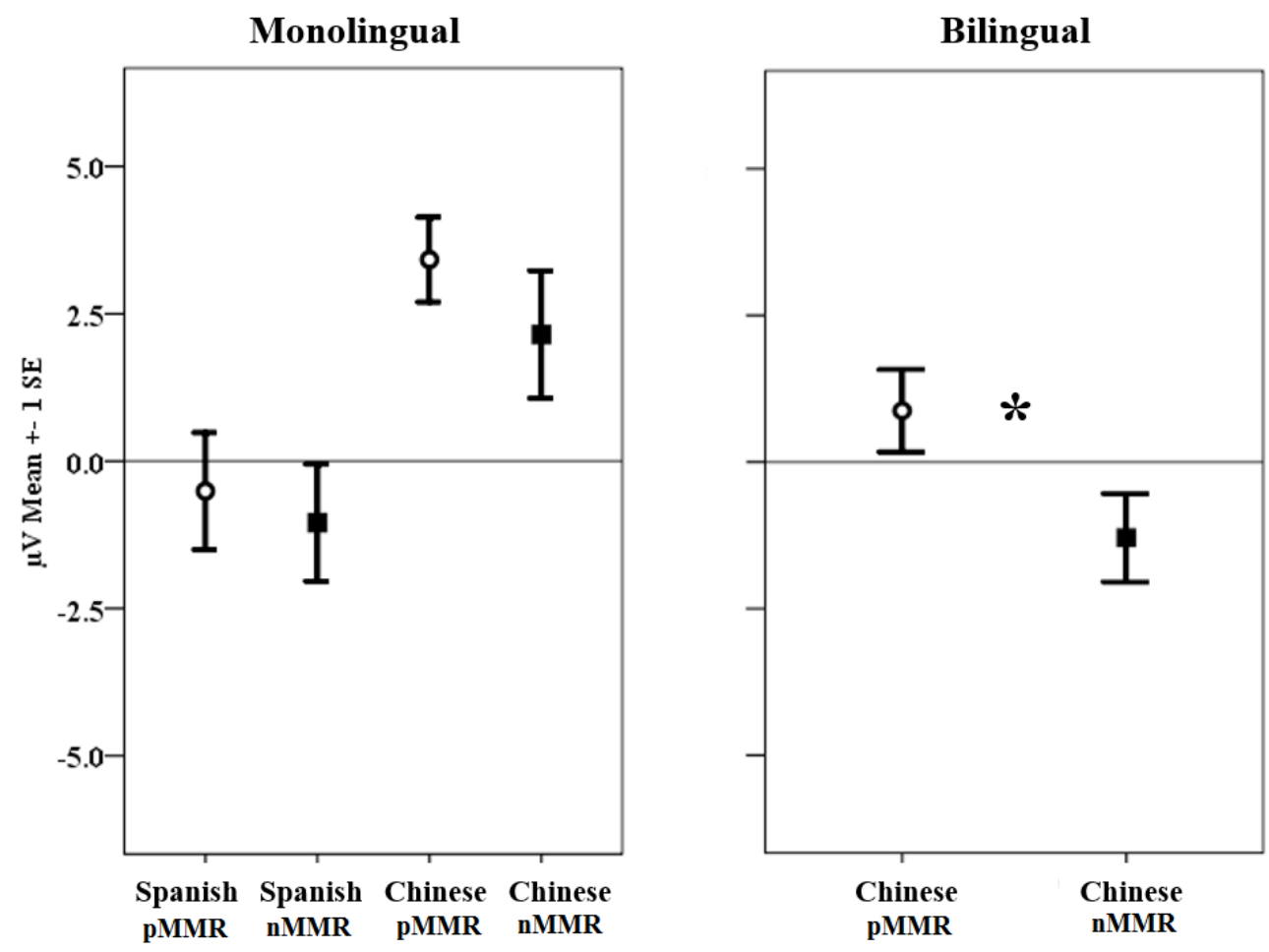

$\operatorname{pMMR} \bigcirc$
$\operatorname{nMMR}$

Figure 6. Panel A. Difference waveform mean amplitudes for monolingual and bilingual infants for native speech contrast(s) as a function of amount of language input. The left panel depicts the English contrast for monolinguals and bilinguals, and the right panel depicts the Spanish contrast for bilinguals. Panel B. Difference wave form mean amplitudes for monolingual (left panel) and bilingual (right panel) infants for non-native speech contrast(s). 